\title{
LA CULTURA TEOLÓGICA DE LAS ELITES LETRADAS. ¿ESPECULACIÓN TEÓRICA O PRAGMATISMO EN EL TUCUMÁN DEL SIGLO XVIII?
}

\author{
POR \\ Silvano G. A. Benito Moya \\ Centro de Estudios Históricos «Prof. Carlos S. A. Segreti» (Unidad asociada a CONICET) \\ Universidad Católica de Córdoba - Universidad Nacional de Córdoba
}

\section{RESUMEN}

Los estudios teológicos de la principal formadora de las elites del Tucumán, la Universidad de Córdoba, le sirvieron en su proceso de dominio del campo simbólico y también en la legitimación que de sí mismos realizaron los grupos de poder. Contrariamente a lo sostenido por los historiadores tradicionales la universidad colonial no estuvo ajena a los problemas sociales y políticos a los cuales se buscó dar solución también desde la teología.

Se distinguen dos momentos bien definidos durante el siglo XVIII, una primera etapa hasta 1767 y, otra segunda, desde la expulsión de los jesuitas hasta 1810. En éstas se estudian las corrientes del probabilismo, probabiliorismo, regalismo, galicanismo y jansenismo, desde la perspectiva de cómo se contribuyó a solidificar un determinado orden social y una cultura legítima y a sujetar los lazos de los súbditos para con sus soberanos, ligando mejor a la sociedad con el aparato de dominación.

PALABRAS ClAVES: Teología moral, Universidad de Córdoba, reformismo borbónico, probabilismo, probabiliorismo, regalismo, elites académicas.

\section{THE THEOLOGICAL CULTURE OF THE LEARNED ELITES. THEORETICAL SPECULATION OR PRAGMATISM IN 18TH CENTURY TUCUMÁN?}

\begin{abstract}
Theological studies of the primary center of formation for the Tucumán elite, the University of Córdoba, helped in the University's process of mastering the symbolic realm and aided the process of self-legitimization that the power centers carried out. Contrary to the claims of traditional historians, the colonial university
\end{abstract}


was not aloof from social and political problems; problems for which they tried to provide theologically based solutions.

There are two distinctly defined periods during the $18^{\text {th }}$ Century, the first stage lasting until 1767, and the second stage ranging from the expulsion of the Jesuits until 1810. In this work, probabilism, probabiliorism, regalism, gallicanism, and jansenism are analyzed from the perspective of how they contributed to the solidification of a particular social order and legitimate culture, holding together the bonds between subjects and their sovereign, better unifying the society under a system of domination.

KEY WORDS: Moral theology, University of Córdoba, Bourbon reforms, probabilism, probabiliorism, regalism, academic elites.

Recibido/Received 08-11-2011

Aceptado/Accepted 15-05-2012

La real cédula de Carlos III de 1776 que creaba el virreinato del Río de la Plata, integró a la antigua gobernación del Tucumán que había pertenecido hasta entonces al virreinato del Perú. Abarcaba las ciudades y jurisdicciones de Santiago del Estero - su capital-; Córdoba - la más poblada y próspera-; Salta - que le seguía en importancia y que en algunos momentos ejerció como capital -; Tucumán; Jujuy; La Rioja; y Catamarca, entre las principales. Luego, con la real ordenanza de intendentes de 1782, las antiguas ciudades y sus satélites conformaron las sendas intendencias de Salta y Córdoba del Tucumán, a la que se unió el corregimiento de Cuyo.

Los espacios letrados de formación de las elites regionales fueron diversos: las escuelas de primeras letras - conventuales o de los cabildos-que existían en cada ciudad; las casas de formación del clero regular, donde se aceptaba también a los miembros de los grupos de poder que no tuvieran como norte la carrera eclesiástica, y que según el tiempo y la orden religiosa fueron itinerantes en su ubicación geográfica; y la formación privada, mediante preceptores que iban a domicilio o recibían en sus casas.

Para la mujer, además de la educación particular, el monasterio femenino fue un espacio que sirvió a tal fin - se aceptaba a niñas que no necesariamente ingresaban luego como novicias-. Los dos más antiguos y únicos que tuvo la gobernación se fundaron en Córdoba en el temprano siglo XVII dedicados a Santa Catalina de Sena (1613 - dominicas) y San José (1628 - carmelitas descalzadas). El Carmelo fue el primero del virreinato del Perú, pero nunca admitió educandas porque su regla lo prohibía, sólo el de Santa Catalina lo hizo. ${ }^{1}$ Desde

${ }^{1}$ Nieva Ocampo, G.; González Fassani, A. M. 2008 «Relicario de vírgenes. Familia monástica en 
1772 el obispo Fr. José Antonio de San Alberto estableció en la misma Córdoba el Colegio de Huérfanas y lo puso a cargo de beatas que educaron no sólo a niñas en condición de orfandad, sino también a educandas de la elite.

Las principales instituciones culturales de la gobernación, que coadyuvaron a la formación de los hombres de letras estuvieron en la ciudad de Córdoba durante todo el período colonial. La centralidad geográfica de esta comarca, unida a una relativa prosperidad económica frente la propia pobreza de la capital de gobernación y, su rol vinculante con las otras gobernaciones del Río de la Plata y del Paraguay, decidieron las preferencias de muchas órdenes religiosas, a quienes los grupos de poder de entonces les delegaron la transmisión a sus miembros de los valores imperantes del «deber ser», los recursos simbólicos y los sistemas conceptuales sobre los que giraron sus representaciones colectivas que los legitimaban como tales.

La Compañía de Jesús que tuvo una actuación sin igual en toda la gobernación se estableció permanentemente en la ciudad en 1599 y estableció allí la cabecera de la provincia del Paraguay erigida en 1604. En 1610 fundó el Colegio Máximo para la formación de los miembros de la orden que luego partirían a ocuparse de la evangelización de las misiones de guaraníes, que formaban parte de la misma provincia religiosa.

El colegio fue el punto de partida para que se abriera otro en 1613, destinado a la formación de los «hijos de vecinos de esta gobernación y de la del Paraguay», como dice la escritura de donación de su fundador el obispo del Tucumán Fernando de Trejo y Sanabria que otorgó al primer provincial jesuita Diego de Torres. ${ }^{2}$ Por breve apostólico de Gregorio XV concedido a la Compañía de Jesús se transformó en la Universidad de Córdoba del Tucumán. Así, en un conjunto edilicio que abarcaba una manzana y parte de otra, tenía inicio o destino una compleja red de información que incluía a la corporación universitaria, al Colegio Máximo, al noviciado jesuita y al Provincialato y su cuerpo consultivo. Cada una diferenciada entre sí espacialmente y con sus propias autoridades encargadas del control y administración de esa red de información, poder, socialización y sociabilidades, por lo menos hasta el extrañamiento de la orden en 1767.

el convento de Santa Catalina de Córdoba del Tucumán (1730-1750)», en C. Folquer (ed.), La Orden Dominicana en Argentina: Actores y Prácticas: 23-54. Tucumán: Universidad Nacional Santo Tomás de Aquino, Instituto de Investigaciones Históricas.

${ }^{2}$ «Escritura de fundación de la Universidad, otorgada por el Ilustrísimo Señor Obispo del Tucumán, Fray Fernando de Trejo y Sanabria. 19 de junio de 1613», en Constituciones de la Universidad de Córdoba: 1. Córdoba: Universidad Nacional de Córdoba, Instituto de Estudios Americanistas, 1944. 
A fines del siglo XVII se les uniría el Colegio de Nuestra Señora de Monserrat, fundado por un egresado de la universidad el Dr. Ignacio Duarte y Quirós y puesto al cuidado de los jesuitas. Fue el encargado de alojar y disciplinar a los miembros de las elites universitarias y, que provenían no sólo de la gobernación, sino también de las homónimas aledañas del Río de la Plata y del Paraguay, e incluso reclutaba estudiantes de la Capitanía General de Chile y del Alto Perú y Bajo Perú.

Desde 1699 el seminario conciliar del obispado se trasladó desde Santiago del Estero a Córdoba y desde 1756 sus seminaristas comenzaron a estudiar en las aulas universitarias. También las órdenes de la Regular Observancia de San Francisco y de La Merced tuvieron estudios y casa de formación en la ciudad.

Un ligero repaso de las principales instituciones encargadas de la transmisión, legitimación y, en algunos casos de la elaboración del conocimiento dominante, al igual que de la generación de espacios de sociabilidad cultural de las elites de la gobernación del Tucumán tuvo como centro a Córdoba y la principal de todas ellas fue su universidad, ya que a su alrededor gravitaron las demás. Algunas instituciones lo hicieron en forma directa, como el seminario conciliar que enviaba sus estudiantes a esta casa de altos estudios; o, en forma indirecta como los estudios conventuales de mercedarios y franciscanos, los primeros eran convocados como participantes activos en los certámenes públicos organizados por la universidad, donde se disputaban argumentos filosóficos, jurídicos y teológicos que legitimaban el orden vigente. Los segundos, además de la ocupación de argüir en dicho teatro público, fueron quienes quedaron a cargo de la corporación universitaria luego de la expulsión de los jesuitas hasta 1808. Por eso la vitrina por excelencia para la visibilidad y formación de estos grupos masculinos fue la Universidad de Córdoba del Tucumán.

Al estudio de su proyecto de formación cultural jurídico-teológica dedicaremos este trabajo, pues en el estudio del conocimiento dominante que se apropió la institución y, dentro de él, las ideas propias y ajenas que buscaron producir discursos de legitimación del orden social, no se puede soslayar el pensamiento teológico en su vertiente moral y canónica. La teología estuvo muy unida al derecho natural y positivo, cada uno con su ámbito específico aunque, a veces, sea difícil desentrañar cuál tuvo mayor influencia sobre el otro, pues en la praxis se mostraron mutuamente engarzados.

Para Tau Anzoátegui tres órdenes normativos regulaban la sociedad hispanoindiana: la religión, la moral y el derecho. Los estudios teológicos eran la base sustentante de todo ordenamiento y organización.

Antonio Hespanha ha dicho que, partiendo de la teoría tradicional del derecho y pasando por la sociología y antropología encontró una inspiración fontal en la teología moral. Ana María Lorandi considera haber hecho el camino 
inverso, pues ha partido desde la antropología e incursionado en la historia política desde la problemática de la teología moral, para terminar en la historia del derecho. ${ }^{3}$ Ambos autores, más allá de los fenómenos estudiados, reconocen el influjo de la teología moral, para acercarse a la dinámica social y política.

Para estudiar en qué consistía la formación jurídico-teológica impartida desde la universidad y cuáles eran sus contenidos hay que señalar dos etapas, comunes a todas las universidades que administraron los jesuitas en América. El sistema o los sistemas vigentes hasta la expulsión, es la primera fase y, la otra, lo que sucedió con este centro luego de 1767. En ambos momentos queremos dar respuesta a la pregunta formulada en el título, que resume un viejo cliché en muchos estudios acerca de la formación de la Universidad de Córdoba en la época colonial, sobre todo en el largo siglo XVIII que será el período estudiado aquí.

Se repite aún, sin la menor evidencia documental, argumentos elaborados sobre todo a fines del siglo XIX y, originados en el concepto sarmientino sobre la Universidad de Córdoba explicitado en su Facundo. El mito se ha forjado en torno a que la corporación cordobesa, cuya Facultad principal fue la de Teología, hasta 1791 que se creo la carrera de Leyes, se habría ocupado de entelequias y, en algunos casos discusiones bizantinas. Mucho contribuyeron a ello los escritos de dos de sus egresados Gregorio Funes y Juan Ignacio de Gorriti, cuyas obras se publicaron en los tempranos años de las emancipaciones y tuvieron como objeto criticar duramente la dominación colonial y su sistema ideológico. ${ }^{4}$

${ }^{3}$ Lorandi, A. M. 2008. Poder central, poder local. Funcionarios borbónicos en el Tucumán colonial. Un estudio de antropología política: 11. Buenos Aires: Prometeo; Hespanha, A. 1993. La gracia del Derecho. Economía de la cultura en la edad moderna. Madrid: Centro de Estudios Constitucionales.

${ }^{4}$ Gregorio Funes afirmaba: «la teología no gozaba de mejor suerte. Lo mismo que la filosofía experimentaba su corrupción. Aplicada la filosofía de Aristóteles a la teología formaba una mezcla de profano espiritual. Se había abandonado el estudio de los padres para dar lugar a cuestiones frívolas é impertinentes.

Razonamientos puramente humanos, sutilezas, sofismas engañosos, esto fue lo que vino a formar el gusto dominante de estas escuelas. Allegábase a esto, que habiéndose introducido el espíritu de facción así en la filosofía como en la teología, vino en su compañía el furor de las disputas. Era cosa lastimosa ver arder estas aulas en disputas inútiles, donde desatendido el provecho, sólo se buscaba la gloria estéril de un triunfo vano. Para esto era preciso inventar sutilezas, y distinciones con que eludir las dificultades. Y así se hacía». (Ensayo de la Historia Civil del Paraguay, Buenos Aires y Tucumán: 308, vol I (1910), vol. II (1911) Buenos Aires: Rosso y Cía - $1^{a}$ edic. 1816 a 1817). Juan Ignacio de Gorriti decía: «un doctor de las universidades de los dominios españoles, sabia bastante cuando havia tranqueado los tomarrones de Goti, Gonet, Suarez y Vazquez, llenando su cabeza de sutilezas escolasticas, y versadose en forjar sofismas para envolver á un antagonista; si podia referir el catálogo de los concilios generales, enumerar las heregias, conciliar algunas aparentes contradicciones de los libros sagrados, se le consideraba como un pozo de ciencia: era un hombre eminente.

Si se trataba de materia morales, el que habia estudiado al padre Concina, leido á Ligurio ó Colet ó algunos de esos otros fabricantes de pecados mortales, era un hombre de consejo. 
Pensamos que la teología, durante el siglo XVIII, tanto durante la administración jesuita como franciscana de la universidad, no estaba alejada de los problemas sociales y, constituida de presupuestos culturales acumulados de larga data, daba directrices. La teología moral y el derecho canónico no se ocupaban de temas ultrasociales. En la Universidad de Córdoba el contenido de su enseñanza estaba comprometida con la realidad social y local en muchos casos, ambos le servían al futuro sacerdote en el mejor cumplimiento de sus deberes de párroco o capellán, pero sobre todo en el ejercicio del confesionario, tanto de españoles como de indios. No hay que olvidar que se compartían las aulas con los estudiantes jesuitas del Colegio Máximo, cuyo destino general era la labor evangelizadora en las misiones guaraníticas, por ello aprendían también la lengua guaraní en el mismo colegio, no en la universidad.

Igualmente en la etapa jesuita como franciscana los lectores universitarios producen y transmiten discursos de legitimación del orden social a través de la teología y la jurisprudencia canónica.

Las fuentes primarias que han sobrevivido para estudiar este fenómeno son escasas y no basta la presencia de determinados libros en sus bibliotecas como testimonio fiel de lo que se impartía efectivamente en las aulas. Los estudios pioneros de Lucien Fèbvre y Henri-Jean Martin, ${ }^{5}$ Rudolph Hirsch, François Furet, ${ }^{6}$ y los más recientes de Roger Chartier, Armando Petrucci, María del Carmen Álvarez Márquez ${ }^{7}$ entre otros, advierten de que la existencia de ciertos títulos en una librería no implicaba su lectura, es más, su ausencia en determinado repositorio no necesariamente indica su desconocimiento o posible lectura

En materias de jurisprudencia canónica, era un grande hombre el que conocia el cuerpo del derecho segun el orden de sus títulos y de las materias de que se trataba en él. El que sabia distinguir entre la autoridad del decreto de Graciano, la de las decretales de Gregorio nono, Clementinas y extravagantes, el que conocia los canonistas célebres, y se hallaba en estado de decir lo que sobre una materia dada opinaba Fagnano, Reinfestuel, Wan-Spen y algunos otros» (Reflexiones sobre las causas morales de las convulsiones interiores de los nuevos estados americanos y examen de los medios eficaces para remediarlas: 204, 1916 Buenos Aires: La Cultura Argentina - $1^{\mathrm{a}}$ edición 1836).

${ }^{5}$ Febvre, L.; Martin H.-J. 2005. La aparición del libro. México: Fondo de Cultura Económica [1958].

${ }^{6}$ Hirsch, R. 1990. «Imprenta y lectura entre 1450 y 1550»: 27-70; Furet, F. 1990. «La librairie del reino de Francia en el siglo XVIII»: 169-206, en A. Petrucci (ed.), Libros, editores y público en la Europa moderna. Valencia: Edicions Alfons el Magnànim.

${ }^{7}$ Chartier, R. 1996. El mundo como representación. Estudios sobre historia cultural. Barcelona: Gedisa; Chartier, R. 1994. «De la Historia del libro a la Historia de la lectura», en Libros, lecturas y lectores en la Edad Moderna: 16-17. Madrid: Alianza; Petrucci, A. 1999. Alfabetismo, escritura, sociedad. Barcelona: Gedisa; Petrucci, A. 2003 La Ciencia de la Escritura. Primera lección de paleografía. Buenos Aires: Fondo de Cultura Económica; Álvarez Márquez, M. del C. 2000. El libro manuscrito en Sevilla (siglo XVI). Sevilla: Ayuntamiento de Sevilla- Servicio de Publicaciones; Álvarez Márquez, M. del C. 2007. La impresión y el comercio de libros en la Sevilla del Quinientos. Sevilla: Secretariado de Publicaciones de la Universidad de Sevilla. 
fuera de ese ámbito. Los libros eran caros y a ello se sumaba su escasez en América comparada con la circulación que de ellos había en la Península, por lo que transitaban mediante préstamos, prendas, ventas, etc. Por todo esto se debe tener precaución a la hora de estudiar las doctrinas y las corrientes teológicas y canónicas que se enseñaron en cualquier ámbito, en este caso la universidad hispánica, pues las bibliotecas no siempre son muestra de lo que ciertamente se impartía. No todo el acervo de conocimiento contenido en una biblioteca universitaria o en su inventario era citado y utilizado por el profesorado universitario, sólo una modesta selección era trabajada en las aulas. Mucho más en la Universidad de Córdoba, sobre todo en la primera mitad del siglo XVIII, donde la biblioteca servía no solamente a los fines de la corporación universitaria, sino a los del Colegio Máximo, noviciado de la Compañía de Jesús, necesidades del provincial - que habitualmente residía en Córdoba - y su cuerpo consultivo.

Para el estudio de toda idea impartida y sostenida desde las aulas, además de los libros hay que buscar fuentes primarias, como las propias producciones de los profesores y alumnos - tractatus y conclusiones-; disposiciones de los claustros; correspondencia epistolar de lectores y estudiantes; y toda otra fuente alternativa que refleje el uso del libro; su asimilación y apropiación de contenidos; la crítica a las diversas formas de concebir el mundo por los autores. Tampoco basta que un libro se quiera imponer desde las reglamentaciones internas, pues ya ha quedado probado que lo escrito en solemnes constituciones no se llevaba siempre a la práctica, muchas veces por razones más que simples: falta de presupuesto para comprar ejemplares de las obras en boga que se querían introducir.

Para el estudio de esta problemática en el período jesuita de la universidad existen dos tractatus, que se dictaron en el curso lectivo de 1734 y que fueron encuadernados en un tomo, junto a otros dos. Todos reflejan el contenido de la enseñanza del tercer año de las cuatro cátedras que componían la Facultad de Teología. Los dos que nos servirán en este trabajo corresponden, uno a la cátedra de teología moral a cargo del jesuita húngaro Ladislao Orosz: Tratado sobre la bula de cruzada y, el de la de cánones, dictado por el jesuita español Fabián Hidalgo: Tratado acerca de los impedimentos de matrimonio. ${ }^{8}$ En el

${ }^{8}$ Contiene cuatro cursos correspondientes al tercer año de la Facultad de Teología que se dictaron desde el 12 de marzo al 15 de noviembre de 1734. Así podemos leerlo en su portada mayor:

Quatrienni / Theologici / TOMUS seu ANNUS III / In Quo de Deo, de reliquis IMPEDIMENTIS / Matrimonii, de PERFECTIONIBUS CHRISTI / et de BULLA CRUCIATæ quatuor / Tractatibus Agitur.

Cada uno de los trataditos posee una portada en el orden siguiente:

[f. 1r.] IH[ESU]S

Tractatus / de / Deo Optimo Maximo / Dictatus a P[atre] Brunone Morales Societatis / IESU / S[acra] Theologia Professore Primario et / Studiorum Prafecto in Collegio / Cordubensi / Anno 1734. 
primer caso es un curso que el propio autor declara que lo concluirá al siguiente año y, en el segundo, se trata de parte central del que inició el año pasado de 1733 y lo continuará en 1735; de ambos se han hecho transcripciones paleográficas y traducciones. ${ }^{9}$

Los datos biográficos de los dos jesuitas de los que poseemos los cursos que impartieron, puede dar idea que cómo estaba formado el profesorado universitario de esa época. El húngaro Ladislao Orosz había nacido en Csizer en 1697 y había ingresado a la Compañía de Jesús de Austria en 1716. Cursó sus estudios de filosofía y, los de teología en el Instituto Pazmaneum de Viena entre 1722 y 1726. Elegido para pasar a la Provincia del Paraguay, cumplía su deseo de dedicarse a la evangelización de los indios. No obstante ello, terminó sus estudios teológicos en Sevilla y allí mismo fue ordenado sacerdote. Llegó a Buenos Aires en 1729 y desde allí se lo destinó a Córdoba, donde ejerció la docencia junto a diversos cargos, como rector del Colegio de Monserrat y luego secretario de provincia. En 1744 fue elegido procurador de provincia ante las cortes de Madrid y Roma, pero viajó recién en 1746. Entre los hombres de la Compañía que llevó consigo estaban el español Domingo Muriel y el germano Florian Paucke. Llegó a Buenos Aires y fue interinamente rector del Colegio de San Ignacio en aquella urbe, pero ya en 1751 continuaba como rector del Colegio de Monserrat, a donde instalará la primera imprenta del Tucumán y Río de la Plata. En 1757 se lo nombró cancelario de la universidad y luego nuevamente volvió como rector monserratense.

Frente al Tratado de Madrid de 1750, por el cual siete misiones jesuíticas quedaron bajo la órbita portuguesa, trató en sus informes, como consultor de provincia, de disuadir a las autoridades virreinales y a la Audiencia de Charcas del despropósito de los traslados indígenas, arraigados a su tierra.

[f. 89r.] IH[ESU]S

Prosecutio Tractatus / de / Impedimentis Matrimonii / a P[atre] Fabiano Hydalgo Societatis IESU / S[acra] Theologia Professore in Collegio / Cordubensi./ Anno 1734.

[f. 149r.] IH[ESU]S

Tractatus / de Perfectionibus Christi / a P[atre] Eugenio Lopez S[acra] Theologice / Professore in Collegio Cordubensi / Societatis IESU / Anno 1734.

[f. 223r.] IH[ESU]S

Tractatus / de / Bulla Cruciatæ / a P[atre] Ladislao Oros Societatis IESU / S[acræ] Theologiæ Professore in Collegio / Cordubensi / Anno 1734.

${ }^{9}$ Astrada, E. M., Consigli J. M. 2002. Ladislao Orosz S. J. Tratado sobre la Bula de la Cruzada. Córdoba: Agencia Córdoba Ciencia; Hidalgo, Fabián S. J. 2005 [1734]. Tratado acerca de los impedimentos de Matrimonio (Córdoba, 1734). Estudio, transcripción paleográfica y versión española, por Benito Moya, S. G. A.; De Santis, G. Córdoba: Centro de Estudios Históricos «Prof. Carlos S. A. Segreti». Para las citas de estas obras seguiremos las transcripciones y versiones de estos autores.

Hispania Sacra, LXV

131, enero-junio 2013, 309-359, ISSN: 0018-215-X, doi: 10.3989/hs.2013.010 
En 1764 por haber regenteado la cátedra de teología moral por varios años, se lo designó resolutor de casos de conciencia en la provincia. Siguió permaneciendo en Córdoba donde lo encontró ya anciano la expulsión en 1767. Llegado a Europa, se estableció en Trnava (Reino de Hungría, hoy Eslovaquia) en la universidad que tenía allí la Compañía de Jesús - por otra parte, única en todo el reino-, donde murió en $1773 .{ }^{10}$

Orosz expresaba en 1729, a meses de su arribo a Córdoba, en una carta que dirigía al jesuita Juan Bautista Urbani de la Provincia de Austria que estaba en el Colegio Máximo

«condenado a enseñar la filosofía (sin duda por permisión de Dios, que con esto purga mis pecados) ¿Valía la pena, con la esperanza del martirio, con el deseo de predicar el Evangelio a los infieles, con el ansia de seguir en la vida y muerte a los Apóstoles, con mil géneros de peligros de la vida, en la embarcación por mar, venir aquí a predicar Aristóteles en la escuela, en lugar de Cristo? Me parece V. R. se reirá de ello; yo, por lo contrario lloro». ${ }^{11}$

El desconcierto lo confiesa él mismo - dice: «con confusión mía»-, mientras que el desencanto se trasluce. Pensar que había insistido con cuantiosas cartas al prepósito general de los jesuitas para lograr dedicarse a la evangelización en tierras americanas y había terminado siendo profesor de estudiantes de la elite de las gobernaciones del Tucumán y Río de la Plata.

Sorprende en esa carta la información y actualización que manejaba sobre las misiones, a tan poco tiempo de su arribo, y los detalles geográficos que proporcionaba, hablaba del «Pilcomayo», del «Paraná», del «Chaco», de «Los Chiquitos» sin hacer referencias a si eran ríos, o regiones, o misiones. Esto confirma los estudios sobre el caudal de información que barajaban los jesuitas internacionalmente. Orosz sabía que su lector del otro lado del Océano entendía claramente lo que expresaba. También le dice que «una larga enfermedad de cabeza me ha coartado tanto la pluma y el sentido». Efectivamente, en todas las firmas que de su mano hemos podido encontrar, se advierte la impericia caligráfica y el temblequeo constante.

Poco sabemos sobre la persona y docencia de Fabián José Hidalgo, quien nació al igual que Orosz en 1697, pero en Córdoba (España) e ingresó a la

\footnotetext{
${ }^{10}$ Para mayores detalles de la biografía: Furlong, G. 1936. «Ladislao Orosz, ex profesor y ex rector de la Universidad de Córdoba (1697- 1773)». Estudios 45: 325-347; Furlong, G. 1966. Ladislao Orosz y su «Nicolás del Techo» (1759). Buenos Aires: Theoria; SZABÓ, L. 1984. El húngaro Ladislao Orosz, en tierras argentinas 1729-1767. Buenos Aires: Fundación para el Estudio de la Ciencia y la Cultura.

${ }^{11}$ Strasser, M. 1930. «El Río de la Plata visto por viajeros alemanes del siglo XVIII, según cartas traducidas por Juan Mühn, S. J.». Revista del Instituto Histórico y Geográfico del Uruguay 7: 267-269.
} 
Compañía en 1711. El 8 de abril de 1712 llegó a Buenos Aires como novicio de la orden y su primera escala fue Córdoba, en la antigua gobernación del Tucumán, donde prosiguió sus estudios en la universidad, en la que permanecería por muchos años.

Fue ordenado sacerdote en esa ciudad en 1723. En 1728 entró a la universidad como profesor para dictar el curso de lógica y, desde allí, continuaría con sus alumnos, como era la costumbre, dictando física (1729) y metafísica (1730) - el mismo año en que su par José Angulo lo sucedía en la cátedra de lógica-. En 1731, siendo rector de la universidad Miguel López, entró a dictar en la Facultad de Teología hasta 1735. Entre 1756 y 1758 fue cancelario universitario. Años después se hallaba en Catamarca, con el cargo de ministro de la residencia de los jesuitas en esa ciudad. Allí lo encontró la expulsión el 10 de agosto de 1767. Falleció en Puerto de Santa María (Cádiz) en 1770 a la edad de 73 años. ${ }^{12}$

Tanto los tratados Acerca de la bula de cruzada como el Acerca de los impedimentos de matrimonio reflejan el pensamiento de los dos profesores jesuitas, unido al pretendido por el rector y prefecto de estudios - quienes administraban y ejercían el poder de censura - y el impartido en las aulas. Se advierte en ellos un fuerte pragmatismo en la educación, contrario a lo que esgrimió despectivamente la historiografía de fines del siglo XIX y gran parte de la primera mitad del $\mathrm{XX}$. Detrás de la forma expositiva y argumentativa escolástica, los temas están enfocados hacia los problemas cotidianos a los que deberá hacer frente y resolver el futuro clérigo, para quien está pensado casi todo el aparato de formación.

La bula de cruzada y el matrimonio como institución canónica y su aplicación en una sociedad como la indiana, ocasionaban no pocos vericuetos morales y legales, en los que el estudiante teólogo debía estar empapado para poder tomar decisiones, o saber a quien recurrir por soluciones. Ambos temas estaban candentes en la sociedad cordobesa y del Obispado del Tucumán en siglo XVIII, asuntos que hoy resultarían baladíes. Mónica Martini afirma, por ejemplo, que el matrimonio fue junto al bautismo el sacramento más asiduamente administrado en Indias. ${ }^{13}$

Son dos tratados casuistas, mucho más Hidalgo que Orosz. En ellos no se presenta el «caso hipotético» de modo tradicional, como lo hacen muchos libros

\footnotetext{
${ }^{12}$ Furlong, G. 1952. Nacimiento y desarrollo de la Filosofía en el Río de la Plata 1536-1810: 149 Buenos Aires: Editorial Kraft; Furlong, G. 1969. Historia Social y Cultural del Río de la Plata (15361810). Tomo II El Trasplante Cultural: Ciencia: 193-194 Buenos Aires: TEA; Storni, H. 1980. Catálogo de los jesuitas de la Provincia del Paraguay (Cuenca del Plata) 1585-1768: 142 Roma: Institutum Historicum Societatis Ihesu.

${ }^{13}$ Martini, M.P. 1993. El Indio y los Sacramentos en Hispanoamérica Colonial. Circunstancias adversas y malas interpretaciones: 201 Buenos Aires: Programa de Historia Colonial (PRHISCO-CONICET).
} 
moralistas de época. Quizá en una pretendida didáctica, y conscientes de que están exponiendo una ciencia universitaria a estudiantes, conceptualizan más en torno a problemas generales de la moral y el derecho a partir del objeto puntual que analizan: la bula de cruzada y el matrimonio, en estos casos. Del estudio de temáticas puntuales impartidas en los cuatro años de la Facultad de Teología, el estudiante no sólo recibía un conocimiento especializado de esos fenómenos, sino también un bagaje de hipótesis, de formas de razonar, de corrientes de pensamiento, de citas de ambos derechos: romano y canónico, y de bibliografía, donde había pasado por todos los fundamentos esenciales de esa disciplina.

Sirva como ejemplo que, cuando Hidalgo refuta los argumentos de autores contrarios a una temática de impedimentos matrimoniales, los compara con otros problemas canónicos. Repasa la cuestión de si es válido el matrimonio cuyos esponsales - es decir la promesa pública y legal de contraer matrimonio - fueron celebrados con miedo grave sufrido por uno o los dos contrayentes, y que con en el transcurso del tiempo, antes de la celebración del sacramento, ese miedo se disipó. Aquí introducirá otro tema canónico que le sirve de comparación, equipara el voto de religión, es decir el que debe ser prestado para la profesión solemne entre la clerecía regular o como para «entrar en religión», con los esponsales como voto para entrar al matrimonio, compara ambos y saca conclusiones. ${ }^{14}$

Así se explica lo que queríamos decir antes, el estudiante salía con un conocimiento del derecho canónico y la teología moral mucho más amplio que el de la materia que se estudiaba anualmente, pues se introducían otras cuestiones jurídicas y teológicas.

Para el estudio de la segunda parte del trabajo, luego de la expulsión de los jesuitas, poseemos un tratado de Filosofía Moral dictado por Fr. Mariano Ignacio Velazco en 1774, primero de su docencia universitaria. Si bien la Ética se dictaba en el primer año de la Facultad de Artes, muchos de sus rudimentos eran la base para el estudio de la posterior teología moral y, en muchos casos como éste, incluían algunos de sus problemas..$^{15}$ Del mismo modo nos servirán las reformadas constituciones universitarias de 1784, las llamadas conclusiones universitarias, especie de proposiciones que los estudiantes defendían

\footnotetext{
${ }^{14}$ Hidalgo, F., S. I., De impedimentis matrimonii, disp. V, sect. 2, n. 21.

${ }_{15}$ Mariano Ignacio VELAZCO, Philosophia moralis compendios/sa methode tradditta / conformisque Ange/lice Doctoris men/ti. A P[atre] F[ratre] Mariano Ignacio Ve/lasco Artium Catedra [sic] / Moderatore / Me audiente Emmanuele Josepho / de Leaniz eius minimo discipulo / huiusque Monscerratensis Colle/gii alumno, nono Kalendas / Novembris anni Domini 1774. Existe una traducción del mismo, publicada como: Velazco, M. I. 2009 [1774] Filosofía Moral 1774. Transcripción, traducción, introducción y notas de Celina A. Lértora Mendoza. Buenos Aires: FEPAI. Para las citas seguiremos la versión de la autora.
} 
públicamente y otros documentos sobre la administración universitaria de este nuevo período.

\section{LAS CÁTEDRAS JESUITAS Y SU CONTEXTO HISTÓRICO}

Para dimensionar el verdadero alcance de los contenidos impartidos desde las cátedras y evaluar la actualización de época, como también hasta qué grado la universidad jesuita era una institución inserta en la sociedad y preocupada por los problemas sociales de la región, se hace necesario contextualizar las temáticas que se abordaron en las fuentes estudiadas. A partir de los textos que sobrevivieron de los cursos, se pueden formular algunas hipótesis sobre las preocupaciones del profesorado de la Universidad de Córdoba.

La corporación, entendido su fin último, enseñaba temas capitales para la época, como cualquier universidad del orbe católico europeo. La bula de cruzada y el matrimonio como institución canónica, habían despertado no pocas polémicas en el seno de la Iglesia, luego de la reforma protestante.

Lutero criticó duramente la política externa de la Sede Apostólica, por la venta de indulgencias, entre otras cosas para la construcción de la basílica de San Pedro y negó que el matrimonio fuera un sacramento, es decir una institución divina, sino que para él era un invento humano, un contrato civil entre dos partes que podía romperse cuando una o las dos estuvieran de acuerdo. Aceptaba el divorcio y quitaba de la órbita canónica esta institución, abrogando por una regulación estatal. No fue solamente este hecho, no menos complejo, lo que motivó la reforma católica y una fundamentación más sólida de estos principios, sino toda una situación social imperante, que requería una preceptiva clara. Los puntos de Lutero fueron el detonante. En 1580, por ejemplo, se introdujo por vez primera el matrimonio civil en Holanda, cuya Monarquía no reconoció las solemnidades religiosas católicas de su constitución.

La bula de Santa Cruzada era un documento pontificio que contenía «favores espirituales a quienes - previas disposiciones personales - se comprometían a participar en la lucha contra los infieles, tanto de forma directa (en la guerra) como indirecta (a través de una limosna)». ${ }^{16}$ Ladislao Orosz, dirá en el siglo xviII en Córdoba que «son Letras Apostólicas munidas de un sello de plomo

\footnotetext{
${ }^{16}$ Benito Rodríguez, J. A. 2002. La Bula de Cruzada en Indias, Madrid: Fundación Universitaria Española. El autor aclara en la introducción que al emprender su trabajo doctoral sólo había una obra escrita sobre el tema, que sólo se abocaba a la realidad de la Península, sin entrar en otros reinos de la Monarquía Hispánica. Goñi Gaztambide, J. 1958 Historia de la Bula de Cruzada en España, Vitoria: Seminario Mayor. Hasta la fecha no sabemos que haya habido otro trabajo de características generales en formato libro como el de Benito Rodríguez.
} 
que contienen muchas gracias que la Sede Apostólica concede a los que cooperan para la extirpación de los infieles, ya sea combatiendo personalmente, ya mediante oraciones y limosna». ${ }^{17}$

El origen de este documento, que luego se transformará en una institución de no poca recaudación económica para la Monarquía, es una concesión pontificia a los protagonistas de la Reconquista hispana, transformada en «cruzada» por bula de Alejandro II en 1064, que aprobó la lucha contra los sarracenos y concedió la indulgencia plenaria a todos los que emprendieran la guerra. Urbano II la otorgó por primera vez a toda la Cristiandad, cuando se efectuaba la cruzada de 1166, donde la ciudad de Jerusalén fue conquistada al Islam. Desde Inocencio III se invitó a los españoles a colaborar también con los cruzados orientales, respondiendo a ello Navarra y Aragón y manteniéndose al margen Castilla.

Este es el origen remoto de la institución, pero el que interesa sobremanera para comprender lo enseñado por Orosz desde la cátedra de teología moral es la concesión de 1474 a los Reyes Católicos, luego de un siglo de inactividad guerrera, para financiar la empresa granadina. En 1482 los reyes llegaron a un acuerdo con Sixto IV, ellos atacarían a los moros y éste a los turcos. El papa tomaba un tercio de lo recaudado por la bula de cruzada y el resto era para ayudar a los Reyes Católicos en la campaña. Ese año, el documento pontificio, abundó en más gracias y favores que los anteriores y cientos de cruzados de toda Europa - Francia, Inglaterra, Irlanda, Polonia, Suiza, etc. - pelearon en España movidos por los beneficios económicos y espirituales que obtendrían y, otros tantos, ganaron las indulgencias mediante la limosna.

En 1485 Inocencio VIII prorrogó la bula de manera incondicional, al enterarse de la toma de la ciudad de Ronda y, un año después exhortaba a los Reyes Católicos a terminar la Reconquista para unir fuerzas contra los turcos, renovando la bula hasta la rendición de Granada en 1491.

Alejandro VI (1492-1503) sucesor de Inocencio VIII, la siguió concediendo, poniendo en manos de los Reyes Católicos, además de ese título honorífico por haber ayudado en la empresa granadina, toda una serie de privilegios y rentas de su exclusiva administración. Granada ya había caído, por lo que en España no se justificaba el privilegio pontificio, pero los reyes españoles empezaron a colaborar en la empresa contra los tucos otomanos. Fernando el Católico consiguió la renovación de la indulgencia y su extensión al Nuevo Mundo por la bula Dum turcharum sarracenorumque de 1514 y el breve Nuper felicis recordationis de 1515. Estos documentos no implicaron una especial concesión indiana, sino que

${ }^{17}$ Orosz, L., S. I., De Bulla Cruciate, pars I, disp. I, cap. 1, n. 2 in fine. «Quod sint Litteræ Apostolicæ sigillo plumbeo munitæ continentes gratias multas, quas Sedes Apostolica concedit cooperantibus, sive personaliter militando, sive per preces et eleemosinam [sic] ad extirpationem infidelium». 
la bula estaba presente por una expansión espontánea, lógica y natural, desde la Península. ${ }^{18}$

La primera concesión expresa para Indias la daría Clemente VII en 1529, «en todos los Reinos y señoríos de Su Majestad, excepto el de Nápoles, comprendiendo las Indias en dicha concesión», aquí se introdujeron dos novedades: el privilegio de las estaciones de Roma y la posibilidad de cumplir con Pascua durante el tiempo de Cuaresma. ${ }^{19}$

El «problema de conciencia» llegó con la crítica de Lutero a la venta de indulgencias, no sólo dentro de la órbita de la Iglesia romana, sino de España, pues la bula era una expresa concesión pontificia para sus reinos. Había que justificar desde el punto de vista de «la conciencia» una empresa que proporcionaba muy buenos réditos económicos a la Monarquía, pues los papas con el correr de los años habían ido otorgando más privilegios y prácticamente el total de lo recaudado era administrado por España, el tema de los patentes réditos financieros ha sido estudiado por algunos autores.$^{20}$ De allí el interés que la Monarquía Hispana tenía para que la bula se siguiera concediendo y, cuando algún pontífice se mostraba reticente, movían todo género de influencias, a través de los propios cardenales españoles y de los embajadores ante la Sede Apostólica. Además, esta renta eventual positiva, como ninguna otra, llegaba sin necesidad de estudiadas reformas, solamente con el uso del miedo, es decir del «santo temor de Dios» que existía para la vida ultraterrena. ${ }^{21}$ Para la época de Felipe II, Benito Rodríguez señala que el $8 \%$ de los tesoros que llegaban desde Indias a la Real Hacienda los proporcionaba la recaudación de la bula de cruzada. ${ }^{22}$

Varios teólogos, entre ellos algunos jesuitas, gastaron riachuelos de tinta para tratar de evitar los excesos cometidos en la instrumentación de la bula. Un problema grave para la Monarquía fue el papa Pío V quien se negó a conceder las indulgencias buláticas, y sólo lo hizo luego de su adaptación a los cánones del flamante Concilio de Trento, a fin de eliminar muchísimos abusos. Fue una verdadera reforma en: «la concesión de las indulgencias, la tasación de la limosna, las diversas predicaciones y distribuciones de las gracias de una misma bula y las suspensiones, las violencias y fraudes con los campesinos,

${ }^{18}$ Benito Rodríguez, J. A. 2002: 20-21 y 36.

${ }^{19}$ Ibídem, 37-38 y 41.

${ }^{20}$ Lorenzo Sanz, E. 1980. Comercio de España con América en la época de Felipe II. t. II: 178-184 Valladolid: Instituto Cultural Simancas- Diputación Provincial.

${ }^{21}$ Torres Gutiérrez, Alejando 2000. «Implicaciones económicas del miedo religioso en dos instituciones de Antiguo Régimen: la Inquisición y la Bula de Cruzada», en Milenio: Miedo y religión, IV Simposio Internacional de la Sociedad Española de Ciencias de las Religiones, Tenerife [www2.ull. es/congresos/conmirel].

${ }^{22}$ Benito Rodríguez, J. A. 2002: 30. 
el arrendamiento del producto de las indulgencias, la facultad de componer, la dispensa de los ayunos, la administración de los sacramentos en casas privadas y la conmutación de votos».

En 1569, por la Consueverunt nostri se publicó la bula debidamente reformada, pero no se hizo extensivo su pase a América para evitar el peso de una nueva carga sobre los indios, pues el pontífice había recibido numerosas denuncias del clero regular sobre que eran compelidos a aceptar la bula. Son varias las reales cédulas publicadas en esta época, referidas a que no se predicara ésta a los pueblos de indios, porque se advertían muchísimos abusos y, además, la limosna sería una carga para los neófitos.

Gregorio XIII en 1573 dio forma definitiva al documento pontificio en la adecuación al Tridentino y en cuanto al número de privilegios: se redujo el bienio a un año, aunque en Indias por las distancias siguió durando dos; se concedió indulgencia a los que tomasen la bula por las almas del Purgatorio, indulto de huevos y lacticinios para clérigos y miembros de órdenes militares mayores de sesenta años durante la Cuaresma, y se extendieron las gracias a Sicilia e Indias. Además, simplificó el trámite de la concesión bolática por la Santa Sede, prorrogándola cada seis años, lo que se continuó ininterrumpidamente por tres siglos.

En 1578 el breve In tanta negotiorum mole, procuró que las predicaciones en Indias fuesen bianuales, por la enorme extensión geográfica existente. ${ }^{23}$

Con esta pléyade de reformas, era lógico que un tema central de una cátedra de teología moral en una universidad indiana fuese la bula de cruzada. Todas las reformas de indulgencias, de tiempos, de formas de ganarlas, la casuística de excepciones a la regla que se podían presentar al confesor y las soluciones y consejos que debía proporcionar ameritaban su enseñanza desde la cátedra. Por eso el tratado de Ladislao Orosz, luego de una breve definición sobre las palabras «bula» $\mathrm{y}$ «cruzada» $\mathrm{y}$, sólo un párrafo dedicado a su origen en España ${ }^{24}$ se mete de lleno en el enmarañado problema de las dudas teológicas que pudieran nacer de su aplicación. No hace alusión a los réditos económicos en todo el curso, pues eso era tema de los tribunales de cruzada y del comisario subdelegado que existía en Córdoba, sino que toda su preocupación se dirige, en primera instancia, a que si los privilegios que otorgaba debían ser interpretados en sentido estricto, como pretendían algunos autores, o en sentido lato, inclinándose por lo segundo. Desde allí, desglosará muchos casos de dudas para ganar correctamente las indulgencias que predica.

\footnotetext{
${ }^{23}$ Ibídem, 45-46.

${ }^{24}$ Orosz, L., S. I., De Bulla Cruciatce, pars I, disp. I, cap. 1, n. 3.
} 
La bula, como tal, era una realidad cotidiana en Córdoba: las ceremonias del arribo bianual; el sermón público al que debían asistir ambos cabildos, las órdenes religiosas y todo el pueblo; las ventas de los sumarios; los pedidos testamentarios para su compra como última voluntad; y los usos de su recaudación mostraban que su alcance trascendía el plano religioso y cultural para entrar en ámbitos políticos, sociales y económicos en la ciudad y gobernación.

Ana María Martínez de Sánchez estudiando su aplicación en Córdoba explica que el gobernador del Tucumán Ramírez de Velasco en 1586 había pedido directamente al rey 8 o 10.000 bulas, pues el tesorero de la cruzada del tribunal de Lima le había dicho que no estaban obligados a publicarla en las provincias de Chile y Río de la Plata. La autora constata, además, que la primera vez que se presentó la bula en la ciudad fue en 1589 y su predicación y cobro efectivo desde $1602 .{ }^{25}$

Otra problemática abordada desde las cátedras de la Universidad de Córdoba durante la administración jesuita y, de la que ha quedado testimonio, es sobre el matrimonio canónico. Hablamos que el detonante para una reforma de la institución fue la negación luterana de su «gracia santificante» y el intento de quitarlo de la órbita espiritual en pos de la temporal. Pero el problema de fondo venía desde mucho más atrás y excedía la órbita teológica. Como estaba basado en el libre consentimiento de las partes, la separación de cuerpos y el establecimiento de nuevas uniones y nuevas proles era un hecho común, la bigamia, la poligamia, los matrimonios clandestinos - en donde el consentimiento no era prestado ante la Iglesia - generaba inseguridad jurídica por el singular problema de establecer los herederos por la muerte de uno de los cónyuges, dado que sólo los hijos legítimos tenían derechos sucesorios. El jesuita Fabián Hidalgo, no en vano establece al final del tratado que estudiamos unas Qucestiunculce - preguntas menores - «acerca de los bienes del que contrae nupcias por segunda vez», especificando acerca de las arras, dote matrimonial, bienes gananciales, usufructo de bienes del cónyuge difunto, adquisición de nuevos bienes con los bienes del cónyuge difunto, y otros relacionados con los herederos. ${ }^{26}$

Desde el nacimiento del cristianismo hasta aproximadamente el siglo Ix, la Iglesia aceptó el derecho romano para la institución conyugal, en tanto éste no se opusiera a la moral cristiana o al derecho divino, produciéndose ciertas mejoras en estos aspectos tras el Edicto de Milán, que autorizó el culto cristiano en el Imperio.

${ }^{25}$ Martínez de Sánchez, A. M. 1994. «La Bula de Santa Cruzada. Córdoba del Tucumán en la segunda mitad del siglo XVIII», Archivum 16: 300 .

${ }^{26}$ Hidalgo, F., S. I., De impedimentis matrimonii, disp. IV, sect. IV, quæstiunculæ n. 13-19. 
Ulpiano había sentenciado que «nuptias non concubitus sed consensus facit», esto es, que las nupcias no las hace la cópula sexual sino el consentimiento, pero en el derecho romano el consentimiento tenía que perdurar en el tiempo - la llamada affectio maritalis - , de tal modo que si faltaba, el matrimonio dejaba de existir. El Concilio de Toledo en el año 400, no obstante esto, reconoció el matrimonio clandestino - aquellos no contraídos públicamente o in facie Ecclesice-, como válidos, pues en ellos se daba el suficiente consentimiento matrimonial.

James Casey dice que el derecho matrimonial canónico fue muy casuístico durante los primeros siglos del cristianismo, se adaptaba más a realidades locales o estatales que a una norma monolítica emanada por una «clase clerical dirigente» $\mathrm{y}$, sólo a partir del siglo IX, con el renacimiento carolingio «comienza a tomar forma el derecho eclesiástico o canónico y una red de tribunales eclesiásticos». ${ }^{27}$

Desde el siglo x la Iglesia comenzó a ejercer y exigir jurisdicción sobre el matrimonio, coexistiendo tanto la legislación canónica como la imperial romana. A partir de ese momento la legislación canónica creció de forma acusada y reguló aspectos antes reservados al poder político. La teología, por su parte, - Alejandro de Hales, San Buenaventura, Alberto Magno, etc. - irá perfilando poco a poco el valor del matrimonio como sacramento, es decir, aquel signo sensible que produce una gracia, una ayuda especial, en virtud del mismo sacramento, sirviendo de este modo para el bien de los cónyuges y que supone la materialización de realidades o elementos divinos e invisibles a través de lo humano y visible. Por lo tanto ese matrimonio no podía ser disuelto, pues reflejaba la unión mística de Cristo con su esposa la Iglesia. Es interesante al respecto la polémica entre la Escuela de Bolonia y la Escuela de París en torno a si el matrimonio era un contrato consensual - aquél que se perfecciona por el simple intercambio de los consentimientos - o real - aquél que se perfecciona por la mera entrega de la cosa (traditio rei), objeto de la contraprestación-.

El matrimonio clandestino estaba aceptado, pero por los problemas continuos que generaba cuando públicamente se contraía con una mujer y luego ocultamente se lo hacía con otra, Alejandro III lo había penado con excomunión y el Concilio IV de Letrán (1215) lo había considerado inválido, con la consecuente ilegitimidad de los hijos habidos dentro de él. ${ }^{28}$

\footnotetext{
${ }^{27}$ Casey, J. 1990. Historia de la Familia: 112 Madrid: Espasa- Calpe.

${ }^{28}$ Fornés, J. 1991. «El sacramento del matrimonio (derecho matrimonial)», Manual de Derecho Canónico: 670. Pamplona: Universidad de Navarra, Facultad de Derecho Canónico.
} 
Trento fue el que promulgó como dogma la enseñanza del matrimonio como uno de los siete sacramentos de la Iglesia, de suerte que se considera desde entonces anatema, y por ende excomunión, cualquier consideración en contrario.

El 11 de noviembre de 1563 se aprobó el famoso decreto Tametsi, luego de haberse discutido cuatro proyectos en el seno del concilio, que mandaba celebrar el matrimonio ante el párroco y dos o tres testigos para poder considerarlo válido. De esta forma, la competencia matrimonial venía dada por el domicilio o cuasidomicilio de los contrayentes, por lo que el párroco tenía competencia personal, más que territorial sobre los contrayentes, o sea podía asistir al matrimonio de sus parroquianos en cualquier lugar del mundo. Tenía una postura meramente pasiva ante el consentimiento marital, pues el decreto decía - «præsente parocho»-, aspecto que permitió los matrimonios ex inopinato o «por sorpresa»o llevar al párroco coaccionado hasta el lugar o con engaños. ${ }^{29}$ Por la real cédula de Felipe II de 12 de julio de 1564, se promulgó el decreto Tametsi, como la forma jurídico-canónica admitida del matrimonio en todos los reinos de la Monarquía.

El preámbulo del decreto daba las razones que habían llevado al Concilio a establecer esta forma jurídica:

«Aunque no se puede dudar que los matrimonios clandestinos, efectuados con libre consentimiento de los contrayentes, fueron matrimonios ratos y verdaderos, mientras la Iglesia no los hizo írritos [...]; la Iglesia de Dios no obstante los ha detestado y prohibido en todos los tiempos con justísimos motivos. Pero advirtiendo el santo Concilio que ya no aprovechan aquellas prohibiciones por la inobediencia de los hombres; y considerando los graves pecados que se originan de los matrimonios clandestinos, y principalmente los de aquellos que se mantienen en estado de condenación, mientras abandonada la primera mujer, con quien de secreto contrajeron matrimonio, contraen con otra en público, y viven con ella en perpetuo adulterio; no pudiendo la Iglesia, que no juzga de los crímenes ocultos, ocurrir a tan grave mal, si no aplica algún remedio más eficaz»..$^{30}$

En la cláusula dispositiva del decreto se establece que:

\footnotetext{
${ }^{29}$ Ibídem, 671-672.

${ }^{30}$ El Sacrosanto y Ecuménico Concilio de Trento, versión castellana por I. López de Ayala, texto latino de la edición romana de 1564. París: Librería de Bouret, 1893, sess XXIV, cap. I, Decretum de reformatione Matrimonii: «Tametsi dubitandum non est, clandestina matrimonia, libero contrahentium consensu facta, rata, et vera esse matrimonia, quamdiu Ecclesia ea irrita non fecit [...]; nihilominus sancta Dei Ecclesia ex justissimis causis illa semper detestata est, atque prohibuit. Verùm cùm sancta Synodus animadvertat, prohibitiones illas, propter hominum inobedientiam, jam non prodesse; et gravia peccata perpendat, quæ ex eisdem clandestinis conjugiis ortum habent; præsertim verò eorum, qui in statu damnationis permanent, dum priore uxore, cum qua clàm contraxerant, relicta, cum alia palàm contrahunt, et cum ea in perpetuo adulterio vivunt. Cui malo cùm ab Ecclesia, quæ de occultis non judicat, succurri non possit, nisi efficacius aliquod remedium adhibeatur».
} 
«los que atentaren contraer Matrimonio de otro modo que en presencia del párroco, o de otro sacerdote con licencia del párroco, o del Ordinario, y de dos o tres testigos, quedan absolutamente inhábiles por disposición de este santo Concilio para contraerlo aun de este modo; y decreta que sean írritos y nulos semejantes contratos, como en efecto los irrita y anula por el presente decreto». ${ }^{31}$

El contexto del momento está descrito en detalle en el decreto: los enormes problemas que ocasionaba determinar quienes eran los herederos legítimos si había habido un matrimonio oculto y otro público, sin que se hubieran cumplido las fases jurídicas. Esto llevó a un replanteamiento moral de la institución, más cuando los protestantes aceptaron el divorcio, tras los problemas acaecidos en Inglaterra con Enrique VIII.

La Iglesia católica vino a solucionar un tácito pedido de las monarquías católicas, cuando no, el aunar esfuerzos comunes para mantener y valorar un matrimonio y una familia constituidos por la heterosexualidad, monogamia, indisolubilidad y sacramental, como el modelo de organización social propio del Estado Moderno en el orbe cristiano, y el único estadio válido para alcanzar la plena realización sexual de la pareja, pero con un fin de procreación.

El decreto Tametsi rigió a la Europa católica hasta fines del Antiguo Régimen y estableció los lineamientos formales de la ceremonia religiosa hasta que sucesivamente los gobiernos liberales fueron secularizando la institución. Sin duda, el derecho canónico protestante hizo desestabilizar el poder unívoco de la Iglesia católica, por un lado, porque la moral matrimonial no fue tan severa. Calvino, por ejemplo, aceptó las relaciones sexuales que no tuvieran como fin la procreación, dejándolo a criterio de la pareja, cosa que se prohibió desde el catolicismo. Pero las diferencias fueron de forma, más que de contenido, porque en definitiva, ambas iglesias, la reformada y la contrarreformada, eran concientes de la valoración que representaba el matrimonio para la estabilidad conyugal y familiar. Lutero sostenía en 1537 que «el divorcio o la separación son siempre pecado, salvo en caso de adulterio, porque entonces es Dios mismo el que realiza la ruptura del matrimonio». ${ }^{32}$

La Iglesia católica aceptaba que se disfrutara la relación sexual dentro del matrimonio, siempre que hubiera finalidad de procreación, pues constantemente estuvo vigilante sobre la legitimidad de la prole. En este sentido la vida sexual

\footnotetext{
${ }^{31}$ «Qui aliter, quàm præsente parocho, vel alio sacerdote, de ipsius parochi seu Ordinarii licentia, et duobus, vel tribus testibus Matrimonium contrahere attentabunt, eos sancta Synodus ad sic contrahendum omninò inhabiles reddit; et hujusmodi contractus irritos, et nullos esse decernit, prout eos præsenti decreto irritos facit, et annullat».

${ }^{32}$ Gaudemet, J. 1993. El Matrimonio en Occidente : 321. Madrid: Taurus.
} 
estaba alentada, ya que era obligatoria entre los esposos por el débito conyugal, que evitaba la concupiscencia. ${ }^{33}$

Se estableció que el decreto Tametsi entraría en vigencia treinta días después de publicado en cada parroquia, pero en la práctica no fue así, algunas lo sostuvieron al pie de la letra, otras aplicaron los contenidos a medias, o simplemente no lo respetaron, siempre pensando en Europa. En la América española entró en vigor inmediatamente al pase regio.

En este contexto se produce la obra del jesuita Fabián Hidalgo en 1734, es un denodado esfuerzo por interpretar y explicar este decreto. Su cometido es claro, la disputa número VI - la más larga del tractatus - se refiere al matrimonio clandestino, allí desplegará su elocuencia, las discusiones de los autores que conoce, y sus propias conclusiones para dilucidar esta preocupación, máxime en una tierra como América, donde las mezclas interétnicas habían generado problemas no contemplados por el derecho canónico pensado desde el centro a la periferia. Además, las uniones de hecho eran práctica corriente.

En esa disputa quiere precisar cuál era el verdadero meollo por el cual la clandestinidad constituía un impedimento dirimente, las características que debían reunir el párroco o en defecto su delegado y los testigos, y la función, estructura y pronunciación de las amonestaciones.

Creemos que lo expresado por Guillermo Furlong a mediados del siglo Xx llamando a esta obra «tratadito» - quizá con un dejo despectivo- y que «nada extraordinario» hallaba en él, hoy deba matizarse un poco. ${ }^{34}$ Hidalgo y su obra son el fiel reflejo de su siglo, en el que se advierte un fiel compromiso de llevar adelante en tierras americanas las disposiciones conciliares de Trento y producir discursos de legitimación del poder de la Iglesia y la Monarquía que aquí han aunado esfuerzos. Su fin no es meramente especulativo, sino práctico.

Por otra parte, Mónica Ghirardi en su libro acerca del matrimonio y la familia en la Córdoba del siglo XVIII y primera mitad del siglo XIX ha estudiado la totalidad de los juicios por disenso matrimonial del Obispado del Tucumán desde el siglo XVII. Allí se ven muchos recursos de nulidad y otros tantos de separaciones de cuerpos que se tramitaron en el Juzgado Eclesiástico del Obispado, en los que se alegan las causales expuestas en el curso de Hidalgo. También aparecen otros, como la bigamia, crimen y error en la condición de la persona, que seguramente

${ }^{33}$ Lavrin, A. 1989. «Sexuality in colonial México: A Church dilemma», en Lavrin, A. (ed.), Sexuality and marriage in colonial Latin America: 49-50. Nebraska: Lincoln and London. Sargiotto, E. 1994. «Matrimonio y sexualidad en Hispanoamérica colonial. Tesis historiográficas recientes en los Estados Unidos». Páginas sobre Hispanoamérica colonial. Sociedad y cultura 1: 125.

${ }^{34}$ Furlong, G. 1969: 193-194. 
este jesuita expuso en las partes perdidas del tratado, de las que sólo tenemos referencias fragmentarias aludidas en la conservada. ${ }^{35}$

En un pormenorizado estudio sobre el divorcio en su dimensión histórica, que integra toda la segunda parte del libro de Ghirardi, emergen como causas del recurso de nulidad la violencia y el miedo $(10,4 \%)$; impedimento de afinidad $(18 \%)$; matrimonio por sorpresa (9\%); impedimento de consanguinidad $(7,4 \%)$; por defecto de forma canónica (15\%), entre otras. Todas fueron estudiadas en el curso hidalguiano de 1734 .

La autora analiza los perfiles sociales de los accionantes y socio-raciales de las parejas involucradas, la edad de los contrayentes, los tiempos de duración del matrimonio hasta el pedido de nulidad, la duración de las causas y las penas canónicas, junto a la casuística de cada uno de esos recursos. ${ }^{36}$

En muchos casos los accionantes son personas anónimas que efectúan la denuncia, el conocimiento privado de casamientos clandestinos por relaciones carnales previas al sacramento, las relaciones incestuosas, la bigamia, los lazos sanguíneos entre los contrayentes o ya casados, era motivo suficiente para la delación, pues:

«debe tenerse presente que era considerado falta grave no denunciar estas situaciones, la Iglesia conminaba a los fieles a denunciar uniones defectuosas para las normas canónicas, en este sentido, puede decirse que ambos brazos de la justicia, civil y eclesiástica, actuaban conjuntamente en pro de la conservación del orden social deseado. Es de destacar que en dicha tarea 'el vecindario' actuaba también como órgano de control de significativa eficacia». ${ }^{37}$

A lo expresado por Ghirardi, agregamos la importante «cultura conyugal» que existía en la sociedad, como para conocer claramente los diversos impedimentos canónicos y efectuar las delaciones. A juzgar por los temas tratados en los expedientes ese conocimiento no era propio del sector dominante, sino una cultura generalizada en la que intervenían los de arriba y los de abajo. No en vano fue tan difundida en el período colonial la obra de Fr. Antonio Arbiol, que

\footnotetext{
${ }^{35}$ Ghirardi, M. M. 2004. Matrimonios y familias en Córdoba 1700-1850. Prácticas y representaciones: 221. Córdoba: Universidad Nacional de Córdoba - Centro de Estudios Avanzados. No puede dejarse de mencionar aquí el prolijo trabajo fontal sobre juicios de esponsales, juicios matrimoniales y criminales, realizado por Dellaferrera, N. C. 2008. Procesos canónicos. Catálogo (1688-1888). Archivo del Arzobispado de Córdoba. Buenos Aires: Editorial de la Pontificia Universidad Católica Argentina.

${ }^{36}$ Ghirardi, M. M. 2004: 230-309.

${ }^{37}$ Ibídem, 236.
} 
aconsejaba cómo debía ser el comportamiento dentro del matrimonio para que la familia fuera una institución protegida. ${ }^{38}$

Que en una universidad como la de Córdoba, un profesor jesuita dictara como tema central de su cátedra de derecho canónico, durante por lo menos tres años, un curso de impedimentos matrimoniales, habla del interés social de su enseñanza y de la adaptación de la misma a la realidad local a la que debería hacer frente el egresado.

\section{EL SISTEMA MORAL DEL PROBABILISMO COMO ARGUMENTACIÓN TEOLÓGICA}

La doctrina probabilista hunde sus raíces en la Edad Media, hacia el siglo XII, ya que en la teología la resolución de las «dudas de conciencia» era un tema preocupante. El estado psicológico respecto de la certeza y la duda sobre lo que era pecado, como conducta moral desviada, podía presentar dos distinciones: la duda y la ignorancia, es decir, la ignorancia de la ley podía causar duda, aunque no siempre, porque la duda pertenecía a otro orden de cosas, ya que podía coexistir en una conciencia recta y verdadera.

El primero que formula la doctrina en forma técnica en 1577 fue el dominico Bartolomé de Medina (1527-1580), aunque como decíamos, la tradición venía gestándose desde antaño. El principio, tal como lo enunció, dice que «si una opinión es probable (es decir, si ésta es sostenida por sabios y está confirmada por argumentos sólidos) es lícito seguirla, aunque la opinión opuesta sea más probable»..$^{39}$

Medina distinguía implícitamente un probabilismo objetivo y uno subjetivo. Una opinión probable objetivamente seguida por sabios era legítimo seguirla frente a otras opiniones más probables, producto de un subjetivismo marcado por la ansiedad o la duda de conciencia.

El tema ya lo había tratado Abelardo en su Ethica cuando hacia 1140 restó importancia a la normativa canónica para centrarse en la intención como fuente primaria de la teología moral. Los actos indiferentes no son buenos o malos en sí mismos, sino en su intención, no se peca o no se peca por hacerlos, sino por

\footnotetext{
${ }^{38}$ Arbiol, A. 1791. La familia regulada con la doctrina de la Sagrada Escritura y los Santos Padres de la Iglesia Católica. Madrid: Imprenta Real.

${ }^{39}$ «Si est opinio probabilis [quam scilicet asserunt viri sapientes et confirmant optima argumenta], licitum est eam sequi, licet opposita probabilior est» (Expositio in Primam Secunda Angelici Doctoris D. Thoma Aquinatis, q. 19, a. 6, Venetiis (Venecia) 1590), apud Saranyana, J. I. (dir.); Alejos Grau, C.-J. (coord.). 1999. Teología en América Latina, vol. II/1 Escolástica barroca, Ilustración y preparación de la Independencia (1665-1810): 186. Madrid-Frankfurt: Iberoamericana - Vervuert.
} 
cómo se hacen. El probabilismo tuvo esta raíz dialéctica entre ley y conciencia y maduró en la segunda mitad del siglo Xvi. Casi contemporáneamente, por influencia de otras corrientes antropológicas, comenzaron los debates entre laxistas, probabilistas y tucioristas o rigoristas que monopolizaron prácticamente los debates teológicos desde la segunda mitad del siglo XVII hasta la expulsión de los jesuitas y la posterior disolución de la orden en 1773.

Medina fue seguido por los primeros teólogos jesuitas Gabriel Vázquez y Francisco Suárez y por algunos maestros dominicos como Juan de Santo Tomás y, a partir de allí muchísimos ignacianos construyeron el sistema casi corporativamente, mientras los dominicos lo abandonaron prontamente. ${ }^{40}$

Hasta donde sabemos, los profesores jesuitas de la Universidad de Córdoba fueron probabilistas. El mismo año que se considera que la corporación abrió sus puertas, en 1614, el primer provincial Diego de Torres informaba al prepósito general que en todas las cuestiones referentes a la teología se seguía a Francisco Suárez y, en algunas cosas, a Gabriel Vázquez. ${ }^{41}$ En un claustro celebrado en 1730, cercano a la fecha en que Orosz e Hidalgo dictaron sus cursos, se estableció unánimemente que no se incorporase a la universidad a los estudiantes que hubiesen estudiado artes en escuelas opuestas a la suarística «por lo graves inconvenientes que se experimentan, y por otros maiores que se pueden temer, disminuiéndose el concurso y explendor en los cursos de esta real Universidad». La decisión es tal, que se le solicitaba al padre provincial que aprobara lo decidido en claustro y, de ser necesario, le diese fuerza de ley y, si alguna vez se hiciera una excepción fuese a condición de que cursase un año completo y luego hiciese los exámenes correspondientes «defendiendo siempre las doctrinas suarísticas». ${ }^{42}$ El contenido del claustro se refería indudablemente al probabilismo y a mantener una uniformidad de doctrina.

Cuando en 1699 se trasladó la sede episcopal desde Santiago del Estero a Córdoba, su gestor, el obispo dominico Manuel Mercadillo, intentó pronto abrir una universidad en el convento de predicadores de la nueva ciudad sede. Alegaba que en la Universidad de Córdoba sólo se enseñaban autores jesuitas y el resto de la teología estaba relegada a un segundo plano, cuando las Constituciones de la Compañía establecían que se debía seguir en sus colegios la doctrina de santo Tomás como la más segura y probada.$^{43}$ Aunque los problemas de este obispo

\footnotetext{
${ }^{40}$ Ibídem, 188.

${ }^{41}$ Furlong, G. 1952: 100.

${ }^{42}$ Archivo General e Histórico de la Universidad Nacional de Córdoba (en adelante AGHUNC), Libro de Claustros $n^{\circ} 1$, f. 97r.

${ }^{43}$ Altamira, L. R. 1943. El Seminario Conciliar de Nuestra Señora de Loreto. Colegio Mayor de la Universidad de Córdoba. Córdoba: Universidad Nacional de Córdoba- Instituto de Estudios Americanistas.
} 
con los ignacianos eran especialmente de tipo económico - las rentas eclesiásticas del obispado-, no se puede negar que lo que argumentaba era cierto y que veía a su clero secular formado con textos jesuitas. Él quería restablecer el estudio directo de Tomás de Aquino.

$\mathrm{Al}$ considerar las fuentes que han sobrevivido y en las que se plasmó este sistema que se impartió desde la cátedra, se puede decir que Hidalgo y Orosz son probabilistas, el primero menos acentuado que el segundo, tema que se explica por las materias que dictaban cada uno. Orosz como profesor de teología moral era lógico que expusiera el sistema con mayor profundidad en su curso.

Tal como se viene haciendo, hay que desentrañar las características de esta corriente a través del estudio de las situaciones morales puntuales que se presentaban y que se enseñaban, por eso Orosz cuando explica uno de los privilegios de la bula de cruzada, que autorizaba a un confesor con aprobación del ordinario a absolver casos reservados al obispo, despliega toda una fundamentación probabilista.

En el capítulo tercero de la disputa II, el jesuita húngaro se pregunta por los privilegios que concede la bula en orden a la elección del confesor y, más que responderla, se esforzará en todo momento por clarificar las características que debe tener ese confesor tanto secular como regular y, en qué casos estaba autorizado para confesar para que el fiel ganase la indulgencia, y en qué casos no lo estaba.

Al entrar en el escabrosísimo tema de las características que debía tener la autorización emanada del obispo para confesar, con el fin de que fuera válida para que ganara la indulgencia el penitente, Orosz se introduce en los casos de quienes poseen título colorado. ${ }^{44}$

Concluye en el capítulo que en casos donde haya defectos de jurisdicción eclesiástica, la Iglesia la suple. Por ejemplo, si un confesor que tenía la licencia del obispo y le fue revocada sin que se enterase y confesara a un penitente, la confesión se considera válida, pues es sólo un defecto de jurisdicción.

«En caso de error con título colorado debe presumirse casi por todos que la Iglesia, como madre piadosa, suple el defecto de jurisdicción confiriéndola, y esto a causa de los gravísimos inconvenientes que sobrevendrán a las almas si la Iglesia, en este caso, no

\footnotetext{
${ }^{44}$ Llámase colorado o aparente, porque sólo tiene el color o apariencia, mas no la realidad de verdadero título para confesar. Está dado por el superior, pero carece de efecto por impedimento oculto de quien lo da o del que lo recibe, por ejemplo: por la excomunión oculta con que se haya ligado el uno o el otro, por irregularidad o porque intervino simonía. También se entiende el título dado sin ningún impedimento, pero ocultamente revocado luego. Ver Donoso, J. 1852. Instituciones de Derecho Canónico Americano. t. II: 4. París, Librería de Rosa Bouret y Cía.
} 
supliera el defecto de jurisdicción; pues bien, estos perjuicios, o al menos hasta ahora siempre gravísimos se seguirían, si la Iglesia no confiriera al confesor la jurisdicción cada vez que él obrara al respecto de su jurisdicción desde una ciertamente probable opinión». ${ }^{45}$

La preocupación moral de Orosz aquí es si la confesión es válida con un confesor con título colorado, donde la resuelve por una opinión probable y objetiva. Cita seguidamente una serie de teólogos que defienden su opinión como Domenico Viva; Francisco Suárez; el cardenal Juan de Lugo; Fernando de Castro Palao; Tommaso Tamburini; Angelo Maria Verricelli; Raffaelo Aversa y Giovanni Dicastillo, para concluir «que en la Iglesia existe el uso, la praxis y la costumbre muy difundida de utilizar esta opinión nuestra; pues bien, si en tal uso, práctica y universal costumbre la Iglesia no supliera el defecto de jurisdicción, evidentemente se seguirían daños que redundan en las almas de los fieles». ${ }^{46}$

Vemos aquí, la fuerza de la costumbre como creadora de derecho, pero su postura está fundamentada en otras igualmente probables. Sus palabras son contundentes: «la sola costumbre es suficiente para que la Iglesia confiera una jurisdicción cierta, pero consta muy ciertamente del testimonio ya aludido de muy importantes testigos que se da tal costumbre en relación al uso de opinión probable en materia de jurisdicción; en consecuencia para el caso del uso de una opinión ciertamente probable en relación a la jurisdicción es cierto que ella es conferida por la Iglesia». ${ }^{47}$

Evidentemente para poder inclinarse por una opinión probabilista, está desechando otras aún más probables como decía la regla. Enumera algunos de los argumentos de «nuestros contrarios», que son de carácter rigorista. Hará entonces un encendida defensa de su probabilismo argumentando que «aquél que absuelve siendo testigo y teniendo conocimiento el Prelado, por quien fácilmente podría ser impedido y, sin embargo no impide; pues bien, el Pontífice ve

${ }^{45}$ Orosz, L., S. I., De Bulla Cruciatce, pars I, disp. II, cap. 3, n. 195. La bastarda nos pertenece. «In casu erroris cum titulo colorato per omnes pene præsumendum est quod Ecclesia pia mater suppleat deffectum iurisdictionis eam conferendo, et hoc ob gravissima incommoda proventura animabus si Ecclesia in hoc casu non suppleret defectum iurisdictionis; atqui eadem incommoda, vel saltem adhuc semper gravissima sequerentur si Ecclesia non conferret iurisdictionem confessori quoties is ex certo probabili opinione circa suam iurisdictionem operatur».

${ }^{46}$ Ídem, «Usum et praxim ac consuetudinem esse in Ecclesia universalissimam utendi hac nostra opinione; atqui si in tali usu et practica ac consuetudine universali non suppleret Ecclesia defectum iurisdictionis evidenter sequerentur gravissima damna redundantia in animas fidelium».

${ }^{47}$ Ibídem, De Bulla Cruciata, pars I, disp. II, cap. 3, n. 196. «Sola consuetudo satis est ut conferatur ab Ecclesia certa iurisdictio; sed constat certissime ex attestatione iam allata gravissimorum testium dari talem consuetudinem circa usum opinionis probabilis in materia iurisdictionis: ergo pro casu usus opinionis certo probabilis circa iurisdictionem certum est eam ab Ecclesia conferri». 
y es conocedor de la praxis utilizada en la Iglesia en relación a una jurisdicción probable, y podría fácilmente impedirla y, sin embargo, no impide [...] No se puede ignorar el uso en la Iglesia, el que frecuentemente testimonian muy serios Doctores de que está vigente en ella: si se hubiera abusado, el Pontífice no sólo podría sino también debería erradicarlo». ${ }^{48}$

La justificación del sistema que hace también es una defensa. Los jesuitas luego de la condena pontificia del sistema de Cornelio Janssens denominado jansenismo, asumieron la bandera antijansenista y se enfrentaron enérgicamente con ellos a lo largo de la segunda mitad del siglo XVII y XVIII, pues las primeras condenas de la silla apostólica datan de 1653. Los jansenistas — dicen Josep-Ignasi Saranyana y Carmen-José Alejos Grau - acusaron a la Compañía de Jesús de ser laxista ${ }^{49}$ desde una actitud superficial y también maliciosa, pues no se pusieron a reflexionar sobre la distinción entre probabilismo objetivo y el subjetivo. ${ }^{50}$

Paralelamente a este debate entre probabilistas y jansenistas, se abrió otro entre probabilioristas y probabilistas. Los penúltimos, embanderados desde algunas órdenes religiosas como la agustina, franciscana y dominica, buscaron un punto medio, un rigorismo moderado que simpatizaba con el jansenismo pero no lo era, en rigor, debido a las condenas de la Santa Sede. Los puntos de controversia se inscribían en la moral y la liturgia -cumplimiento del precepto dominical, indicaciones sobre el ayuno, entre otros-.

Después de las condenas pontificias al jansenismo, Alejandro VII, en sendos decretos de 1665 y 1666, condenó cuarenta y cinco proposiciones laxistas, algunas de las cuales eran sostenidas como probabilistas. El tema provocó no pocos reparos a los jesuitas y que se enfervorizaran los dominicos. Las condenas laxistas continuaron con Inocencio XI, pero el golpe de gracia fue un decreto del Santo Oficio de 1680 alabando la postura probabiliorista del jesuita Tirso González, animándolo a seguir. La Santa Sede comenzaba a alejarse así del probabilismo. ${ }^{51}$

Sin este breve contexto político-ideológico no se comprende acabadamente la defensa que hizo Orosz de la idea probabilista respecto del confesor y su licencia, insistiendo indirectamente que si fuera laxismo, ya la Sede Apostólica lo habría condenado. Tampoco se dimensiona la defensa que ha hecho de sí

${ }^{48}$ Ibídem, pars I, disp. II, cap. 3, n. 197. «Qui absolvit vidente et sciente Prælato a quo facile impediri posset, nec tamen impeditur; atqui Pontifex videt, et conscius est praxis in Ecclesia usitatæ circa iurisdictionem probabilem, eamque posset facile impedire, nec tamen impedit... neque enim ignorare potest usum in Ecclesia quem in ea vigere passim Doctores gravissimi testantur: quem, si abusus foret, non solum posset sed et deberet Pontifex tollere.»

${ }^{49}$ El laxismo autorizaba a seguir la opinión menos probable.

${ }^{50}$ Saranyana, J. I. (dir.); Alejos Grau, C.-J. (coord.). 1999: 32, 189, 194.

${ }^{51}$ Ibídem, 33, 194-195. 
mismo antes, definiéndose como un probabilista objetivo o extrínseco pues «temo profundamente que quizás bajo la hierba verde se oculte una serpiente de ciega pasión». ${ }^{52}$

Pero el profesor de Córdoba lleva la defensa de su probabilismo a niveles altos «pues que algunos pocos nieguen la probabilidad de alguna opinión no quita la certeza de su probabilidad».53

Hidalgo es igualmente probabilista, aunque por las características del tema que trata en su curso, tiene menos posibilidades de desarrollar profundamente ese sistema. Cuando en el parágrafo II de la disputa VI se pregunta por la calidad del párroco para la validez del matrimonio entra a considerar la cuestión de las jurisdicciones, por ejemplo si un cura puede casar a feligreses de su parroquia en otra, donde la jurisdicción es de un párroco diverso. Señala una pléyade de autores a favor y en contra de la licitud, inclinándose por los favorables al hecho «puesto que parece más probable». Luego se encargará de fundamentar que como no se trata de un acto de jurisdicción contenciosa sino voluntaria, no invade el derecho del otro y no hay motivo para que sea ilícita. Claro que, los autores que sigue porque sus opiniones le parecen más probables, son la mayoría jesuitas. ${ }^{54}$

Ahora, ¿cómo se introducía el sistema probabilista en estos estudiantes miembros de las elites del Tucumán y cómo se les enseñaba a defenderlo? Un párrafo de Orosz lo muestra descarnadamente, pues su exacerbación es notoria. Le dice retóricamente al alumno que razone la concatenación de argumentaciones que ha ido desarrollando en torno al tema, donde ha asumido una opinión probabilista. Le enseña que no sostenga lo contrario pues, «afirmando lo primero, te alejarás de la verdad y de casi todos los Doctores; defendiendo lo segundo [es decir el probabilismo] con nosotros, aprenderás de la palabra de muchos, en el hecho tan solo de pocos».$^{55}$ Había bastante de coercitivo en la forma en que se introducía el sistema teológico y si el profesor exponía las tesis en contrario y las refutaba todo el tiempo, difícilmente los estudiantes verían otras formas de resolver los casos presentados.

\section{LA ERUDICIÓN LIBRARIA COMO SUSTENTO DE AUTORIDAD}

El estudio del sistema de citas de «autoridad» - como se gustaba llamarlo en la época - ayuda a comprender, desde otro ángulo, las corrientes de pensamiento

\footnotetext{
${ }^{52}$ Orosz, L., S. I., De Bulla Cruciatce, pars I, disp. I, cap. 4, n. 89, 88.

${ }^{53}$ Ibídem, pars I, disp. II, cap. 3, n. 203.

${ }^{54}$ Hidalgo, F., S. I., De impedimentis matrimonii, disp. VI, sect. I, § II, n. 93, 94.

${ }^{55}$ Orosz, L., S. I., De Bulla Cruciatce, pars I, disp. II, cap. 3, n. 198.
} 
en la universidad cordobesa dieciochesca que influyeron en la formación de los hombres de saber de entonces. Muchas de las fuentes llegaban por vías indirectas, y normalmente la obra más citada era la que se poseía, en la biblioteca, en el aposento, mientras las menos se cosechaban de la misma obra que se consultaba y usaba para enseñar.

Un estudio sobre los libros que tenía la biblioteca y las citas en los tratados de Orosz e Hidalgo, revela que las obras aludidas en mayor número eran las que estaban en los anaqueles, mientras que las otras se conocían en forma indirecta. Muchas veces el propio lector universitario lo hacía notar, usando la preposición «apud» - junto a-, por ejemplo. Su opinión estaba sostenida por el autor consultado, junto a otros generalmente extrapolados de esa fuente que leía.

Aunque en líneas generales, para la primera mitad del siglo XVIII había un predominio de autores jesuitas y probabilistas, no se puede negar que se citaban para el tratamiento de esos temas puntuales a los autores de moda en las universidades, juzgados eclesiásticos, conventos de formación y monasterios del orbe hispánico. Un examen, a través del estudio sobre el matrimonio de la historiadora Daisy Rípodas Ardanaz, muestra que los autores seguidos por Hidalgo eran los consultados comúnmente para la temática en otras latitudes, como Charcas, Lima o México, lo mismo sobre la bula de cruzada según José Antonio Benito Rodríguez y Ana María Martínez de Sánchez.

Algunos eran mencionados con relativa frecuencia por muchos profesores, como el popular Tomás Sánchez (1550-1616), probabilista moderado y autor de una obra profusamente aludida y seguida: Disputationes de Sancto Matrimonio Sacramento, que tuvo numerosísimas ediciones desde la primera en 1592. Orosz lo cita en 47 párrafos e Hidalgo, por obvias razones, en 61. Roberto Peña dice que fue el autor más referido en las causas por divorcio y nulidad canónica del obispado del Tucumán y uno de los pocos jesuitas seguidos luego de la expulsión. Además, agrega que su obra fue ya expurgada en vida del autor y muy atacada por el grupo jansenista de Port Royal y por Pascal en sus Provinciales, quien impugnó su análisis sobre las situaciones matrimoniales por «demasiado libres y aún escabrosas en materias delicadas». ${ }^{56}$

Otros que se mencionan en sendos tratados, con un importante número de referencias, son el oblato milanés Martino Bonacina, ${ }^{57}$ el cardenal jesuita Juan

\footnotetext{
${ }^{56}$ Peña, R. I. 1988. «Fuentes del Derecho Indiano: los autores, Anacleto Reiffenstuel y el Jus Canonicum Universum», Anales de la Academia Nacional de Derecho y Ciencias Sociales de Córdoba 23: 116-117.

${ }^{57}$ Martino Bonacina (1585-1631). Operum de morali Theologia, et omnibus conscientiae nodis... Editio novissima, Lugduni (Lyon), sumptibus Iacobi Cardon (Jacques Cardon ed.), 1633. También la edición: Lugduni, sumptibus Anisson et Ioannis Posuel (Anisson y Jean Posuel eds.), 1697.
} 
de Lugo $^{58}$ y superando ampliamente en citas a estos dos, el jesuita leonés Fernando de Castro Palao, de corte probabilista, al que hace referencia en 15 oportunidades Ladislao Orosz y 33 veces Hidalgo. Según Peña estos tres autores también aparecen mencionados como fundamento en los juicios por disenso matrimonial en los expedientes del Juzgado Eclesiástico del Tucumán colonial. ${ }^{59}$

Martínez de Sánchez, siguiendo a Hernáez, menciona como principales expositores del tema de la bula de cruzada a Fr. Manuel Rodríguez, Alfonso Pérez de Lara, Juan Gil Trullench, Andrés Mendo, Francesco Bardi y Luis Nogueira. ${ }^{60}$ Todos fueron citados por Orosz en su curso, aunque prefirió por el sistema que seguía a los jesuitas probabilistas Mendo y Bardi, con quienes no siempre acuerda.

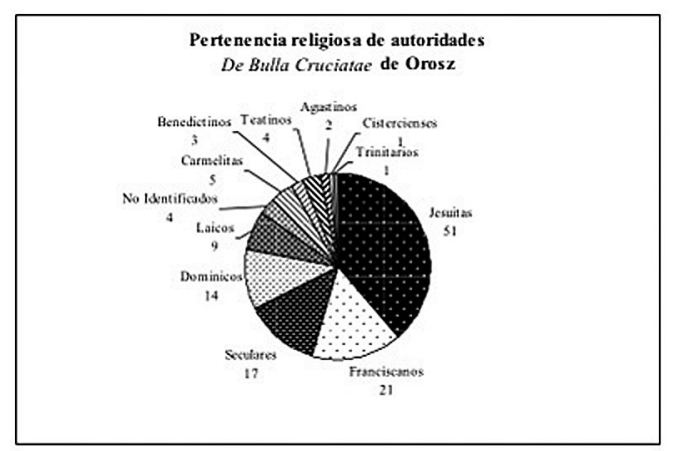

El cuadro muestra la procedencia religiosa o laica de los 132 autores que fueron citados en De Bulla Cruciatce por Ladislao Orosz, donde el predominio de autores jesuitas es contundente frente al de otras órdenes, como franciscanos y dominicos citados con profusión y un importante número de clérigos seculares a quienes hemos denominado simplemente «seculares».

Ya se ha advertido que muchos de estos autores son de segunda cita, por ejemplo Ana María Martínez de Sánchez que está estudiando las citas de autoridad en este tratado, afirma que muchas referencias provienen del jesuita logroñés Andrés Mendo. ${ }^{61}$ Asimismo la autora en una minuciosa identificación de

${ }^{58}$ Juan de Lugo, card. (1583-1660); Disputationes de Iustitia et Iure... Editio novissima a mendis expurgata, Lugduni (Lyon), sumpt[ibus] Philippi Borde, Laurentii Arnaud, et Claudii Rigaud (Philippe Borde, Laurent Arnaud y Claude Rigaud), 1652.

${ }^{59}$ Peña, R. I. 1988: 119, 123.

${ }^{60}$ Martínez de Sánchez, A. M. 1995. «De lo pecuniario a lo espiritual: la Bula de Composición», Revista de Historia del Derecho, 23: 216.

${ }^{61}$ Martínez de Sánchez, A. M. 2008. «Ley y doctrina en el Tractatus de Bulla Cruciatæ de Ladislao Orosz», en Puente Brunke, J. de la, Guevara Gil, J. A. (eds.), Derecho, instituciones y procesos históri$\cos$, t. I: 176, Lima: Pontificia Universidad Católica del Perú, Instituto Riva-Agüero. 
obras del curso, reconoce que 17 de ellos escribieron específicamente tratados sobre la bula. ${ }^{62}$

Una constatación de los autores y sus obras, con los que efectivamente estaban en el inventario de la Librería Grande de la Universidad de 1757 revela que aquellos citados con profusión como Bardi (62), Ibañez (5), Mendo (36), Monreal (8), Rodríguez (11) y Tamburini (8), estaban efectivamente en los anaqueles ${ }^{63}$ no así el resto a quienes se hace referencia en una o dos veces. Nogueira figura en la biblioteca jesuítica, pero Alfredo Fraschini advierte que el asiento en el catálogo está escrito de otra mano, es decir fue un libro incorporado con seguridad después de la fecha en que se confeccionó dicho instrumento de búsqueda. Igualmente la obra bolática de Alfonso Pérez de Lara, presente en otras bibliotecas cordobesas ${ }^{64}$ nunca estuvo en la librería universitaria. Ello explicaría por qué en 1734 Orosz se refirió en muy pocas oportunidades a Nogueira y Pérez de Lara, citas tomadas seguramente de fuentes secundarias.

Hidalgo en su De Impedimentis Matrimonii privilegia, como Orosz, los mejores canonistas y moralistas en la materia y, claro está, que estuvieran a su alcance en la biblioteca. Además del jesuita Tomás Sánchez, sigue al igualmente probabilista moderado y casuista Johann Georg Reiffenstuel - más conocido como Anaklet, nombre que tomó en su vida religiosa - citándolo en 39 párrafos.

La obra sobre derecho canónico de este franciscano desde su primera edición en 1700 era muy estimada y había alcanzado un primer puesto entre los canonistas, quienes lo consideraban no superado y portador de nuevos vientos en ese campo. ${ }^{65}$ Roberto Peña afirma que Sánchez y Reiffenstuel son los dos autores más citados en los escritos jurídicos del Juzgado Eclesiástico del obispado tucumanense. Además, muchas otras citas de autoridad dentro de esos alegatos jurídicos se toman de la obra de este canonista bávaro, por lo que «el manejo que hace de las fuentes en que descansan sus proposiciones y tesis, con citas de

${ }^{62}$ Sebastián Acosta de Andrada; Agustín Antolinez; Francesco Bardi; Bernabé Gallego de Vera; Antonio Gómez; Vicente Antonio Ibañez de Aoyz; Andrés Mendo; Miguel Jerónimo Monreal; Pedro Montenegro; Leandro Murcia; Luis Nogueira; Alfonso Pérez de Lara; Diego Ramos; Manuel Rodríguez; Tommaso Tamburini; Martín Torrecilla y Gil Trullench, Ibídem, 176-178.

${ }^{63}$ Para esta identificación seguimos la edición del catálogo Index Librorum Bibliothecae Collegii Maximi Cordvbensis Societatis Iesv, edición al cuidado de A. Fraschini, Córdoba: Universidad Nacional de Córdoba, 2005.

${ }^{64}$ Martínez de Sánchez, A. M. 1995: 222-224.

${ }^{65}$ Johann Georg Reiffenstuel - alias Anaklet- (1642-1703). Ius Canonicum Universum clara methodo iuxta titulos quinque librorum Decretalium. In quæstiones distributum, solidisque responsionibus, et obiectionum solutionibus dilucidatum..., Venetiis (Venecia) apud Antonium Bortoli (Antonio Bortoli imp. ), 1730. En la edición de 1777 en Ausburgo a cargo de Flavio Ricci, el editor le quitó las opiniones probabilistas, corrigiéndolas hacia el probabiliorismo, más acorde con el rumbo oficial que había tomado la moral entre sus compañeros de orden.

Hispania Sacra, LXV

131, enero-junio 2013, 309-359, ISSN: 0018-215-X, doi: 10.3989/hs.2013.010 
los más importantes autores que han tratado la cuestión y avalan su doctrina», es realmente encomiable. ${ }^{66}$

Otro canonista profusamente citado por Hidalgo es el jesuita bávaro Franz Xaver Schmalzgrueber quien enseñó derecho canónico en Dillingen e Ingolstadt entre 1703 y 1716 . Que este jesuita de Córdoba del Tucumán lo citara en 42 párrafos indica a las claras el conocimiento puntual de su obra y su esmerada actualización, pues se trata de un contemporáneo suyo que enseñaba en muchos colegios y universidades ignacianas alemanas. ${ }^{67}$

Recurre igualmente a otros miembros de la Compañía de Jesús que han tratado específicamente el tema matrimonial como Juan Marín ${ }^{68}$ en 30 oportunidades, Ferdinand Krimer ${ }^{69}$ en 20, Georges Gobat ${ }^{70}$ en 11, probabilistas todos, pero más el francés Gobat, acusado de ser sumamente laxo, al punto que algunas de sus proposiciones fueron condenadas por Inocencio XI en 1679, el mismo año de la muerte del autor. Las ediciones que siguieron de su obra como la de 1701 fueron expurgadas de las 32 proposiciones consideradas relajadas. En Francia se desató una oleada de acusaciones contra la moral defendida por los ignacianos en razón de la condena de la obra de Gobat. ${ }^{71}$

\footnotetext{
${ }^{66}$ Peña, R. I. 1988: 126-128.

${ }^{67}$ Franz Schmalzgrueber (1663-1735). Ius Ecclesiasticum Universum, seu quinque libri Decretalium (obra completa). Sponsalia, et Matrimonium seu Decretalium Gregorii IX. Pontif[ex] Max[imus]. Liber IV. Brevi Methodo ad discentium utilitatem expositus. In quo præcipuæ circa materiam huius libri quarti, quæ tum Theoria, tum in Praxi occurrunt, difficultates solvuntur, allatis etiam contra sententium fundamentis, et horum solutionibus..., Ingolstadii (Ingoldstadt), sumptibus Ioannis Andreæ de la Haye bibliopolæ academici (Jean André de La Haye imp. ), Dilingæ (Dillingen), formis Ioann[is] Ferd[inandi] Schwertlen (Johann Ferdinand Schwertlen imp. ), Episc[opalis] Princ[ipalis] Aulæ, et Civ[itatis] Typographi, 1726.

${ }^{68}$ Juan Marín (1654-1725). Tractatus de matrimonio, Matriti (Madrid), typis D[omini] Gabrielis del Barrio (Gabriel del Barrio), 1715. Las citas coinciden con esta obra.

${ }^{69}$ Ferdinand Krimer (1639-1703). Quæstionum Canonicarum, in quinque libros Decretalium... tomus IV In Librum IV Decretalium, per viginti, et unum Titulos distributum De Sponsalibus, et Matrimoniis eorumque impedimentis, ac dispensationibus, cæterisque quæstionibus per singulos eiusdem libri Titulos comprehensis..., Augustæ Videlicorum (Ausburgo), sumptibus Georgii Schlüter, et Martini Happach (Georg Schlütter y Martin Happach), 1702.

${ }^{70}$ Georges Gobat (1600-1679). Operum moralium tomi tres, in quorum primum habentur experientiæ theologicæ sive experimentalis theologia qua casibus plus septingentis factis non fictis explicatur in ordine ad praxim universa materia septem sacramentorum; in secundo... tractatus quinque: I. Clypeus Clementium Iudicum utriusque fori. II. Vindiciæ theologicæ adversus nonnullos iureconsultos. III. Quintuplex iubilæum. IV. Thesaurus ecclesiasticus indulgentiarum. V. Acusatio canonica ebriosi, seu theologia iuridico-moralis; in tertio... tractatus quatuor; I. De votis. II. De iuramentis. III. De blasphemiis. IV. De superstitionibus, Venetiis (Venecia), sumptibus Iacobi Bertani (Giacomo Bertamo), 1716.

${ }^{71}$ «George Gobat», New Advent. Catholic Encyclopedia [www.newadvent.org]
} 


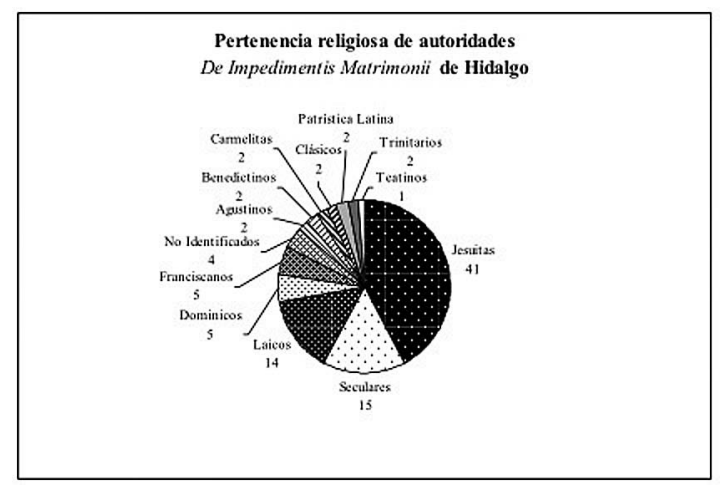

No falta la cita, en 14 oportunidades, del canonista portugués Agostinho Barbosa con dos de sus obras Collectanea doctorum y Pastoralis solicitudinis. ${ }^{72}$ Ambas fueron debidamente expurgadas por mandato inquisitorial en sus primeras ediciones, algunos de estos expurgos, realizados en Córdoba, han quedado manifiestos en los ejemplares de las obras. Las dos eran mencionadas con asiduidad en los alegatos y dictámenes de las causas por disenso matrimonial en el obispado. ${ }^{73}$

El gráfico sobre la procedencia religiosa y laica de los autores aludidos por Hidalgo muestra la misma característica que el de las autoridades citadas por Orosz. Hay un evidente predominio de autores jesuitas y de éstos, la mayoría son probabilistas, al igual que los que pertenecían a otras órdenes. Muchos de los citados por estos profesores, que no son jesuitas, son refutados cuando entran a profundizar en sus cursos.

Bastante se ha dicho sobre las razones que llevaron al obispo del Tucumán Manuel Abad Illana a pedir la entrega de la universidad a los franciscanos, luego de la expulsión de los jesuitas. Había entrado a la diócesis del Tucumán en 1764 y se llevaba mal con su clero criollo; demás está decir que su antijesuitismo era exacerbado. La tesis tradicional, basada en el pedido secreto que el obispo realizó al gobernador Bucarelli y Ursúa - quien llevó a cabo la expulsión en el

${ }^{72}$ Agostinho Barbosa (1590-1649). Collectanea doctorum, qui in suis operibus Concilii Tridentini loca referentes illorum materiam incidenter tractarunt, et varias quastiones, in foro ecclesiastico versantibus maxime utiles, deciderunt. Hac ultima editione ab ipso auctore recognita et quamplurimorum additamentorum accessione sesqui amplius aucta, Lugduni (Lyon), Sumptibus Laurentii Durant (Laurent Durand), 1642 y Pastoralis solicitudinis sive de officio et potestate episcopi tripartita descriptio...: methodo nova et expedita complectitur...; cum sextuplici Indice.Hac postrema editione ab ipsomet auctore... variis resolutionibus illustrata... allegationibus locupletata aliisque insignibus accessionibus cumulata, Lugduni (Lyon), sumptibus Laurentii Durand (Laurent Durand), 1628.

${ }^{73}$ Peña, R. I. 1988: 118. 
Río de la Plata - sostenía que el obispo había solicitado este cambio, contrario a la instrucción del Conde de Aranda que mandaba entregar los establecimientos jesuíticos educativos al clero secular, porque su clerecía había sido formada por los ignacianos y, si lo que se pretendía era erradicar el probabilismo de las aulas no se iba a lograr. Se basaba en la expresión de la instrucción de Aranda que decía «que no sean de su doctrina». ${ }^{74}$

Tras el examen del contenido, predominio, y efectividad de los autores trabajados en este epígrafe no hay dudas de que las palabras del obispo eran ciertas y no se trataba de una estrategia política, independientemente de que haya otras razones igualmente válidas para entender su solicitud. La tesis tradicional en vez de atacarse, debería sumarse a la pluricausalidad histórica.

\section{EL PROBABILIORISMO Y LOS GALICANISMOS: NUEVOS SISTEMAS}

Al estudiar el probabilismo en la universidad se ha hecho alusión al debate sostenido en todo el mundo católico entre probabilistas y probabilioristas, desde la segunda mitad del siglo XVII y el siglo XVIII hasta la expulsión de los jesuitas. También la Compañía de Jesús había abrazado corporativamente el sistema probabilista, salvo algunas voces disidentes como Tirso González de Santalla, a quien los superiores de la Compañía le habían denegado en 1673 el permiso para imprimir una obra titulada Fundamentum theologia moralis, en la que defendía el probabiliorismo.

Este jesuita había recurrido al papa Inocencio XI, quien había hecho examinar sus manuscritos y había decretado en 1680 que los jesuitas eran libres de seguir una u otra doctrina. Aunque González llegó hasta prepósito general en 1687 y, pese a la resistencia dentro de su propia orden en 1694 logró imprimir su obra Fundamentum theologice moralis, id est, tractatus theologicus de recto usu opinionum probabilium con el beneplácito de Inocencio XII, pero no logró mucho más por el probabiliorismo dentro de la Compañía. ${ }^{75} \mathrm{Su}$ obra estaba en los anaqueles de la Librería Grande de la Universidad de Córdoba, aunque nada indica que la misma haya sido usada en la enseñanza, pues en las fuentes conservadas que dan testimonio de lo impartido no hay ni una sola alusión al autor y a su pensamiento. Tampoco se puede suponer, como a veces leemos en algunos autores, que por encontrar mencionada la existencia o compra de tal o cual libro en la universidad, efectivamente se enseñaran determinadas corrientes filosóficas, teológicas o jurídicas. Primero debemos constatar que las obras realmente

\footnotetext{
${ }^{74}$ Altamira, L. R. 1943: 164.

${ }^{75}$ Saranyana, J. I. (dir.); Alejos Grau, C.-J. (coord.). 1999: 195.
} 
se adquirieron, pues muchas veces son simplemente expresiones de deseo, ya que seguidamente o después de un tiempo se afirma que no había habido presupuesto y que la compra todavía no se había concretado. En segundo lugar, como ya hemos dicho, se debe buscar si la obra efectivamente fue consultada y usada en la enseñanza.

Luego de la expulsión de la Compañía, en el plano de las ideas que se enseñaron el cambio se dio en muchos aspectos. En primer lugar, el obispo Abad Illana, quien propuso a los franciscanos para hacerse cargo de las cátedras, era filojansenista aunque rechazara expresamente ese rótulo, además compartía su antijesuitismo con el obispo de Buenos Aires Manuel Antonio de la Torre. ${ }^{76}$

La Orden de la Regular Observancia de San Francisco fue propuesta adrede, pues el probabiliorismo había arraigado fuertemente entre los frailes menores, más que entre los propios dominicos, y habían adoptado corporativamente el sistema en el cercano capítulo general de Mantua en 1762, aunque en 1686 ya había sido prescrito para toda la orden seráfica en unos estatutos aprobados por Inocencio XI. ${ }^{77}$

El decreto de expulsión ordenaba que la doctrina de la Compañía fuese reemplazada en la enseñanza por la de Agustín de Hipona y Tomás de Aquino. $\mathrm{Al}$ año siguiente, y con motivo de un pedido de Buenos Aires para que la universidad se trasladara a esa ciudad, el Consejo de Indias resolvía - haciendo suyo el dictamen del fiscal (abril de 1768) - , que la universidad debía quedar en Córdoba por estar «más en el centro y tierra adentro», desterrándose la doctrina jesuita por la de Agustín y Tomás. ${ }^{78}$ Ese mismo año, en el mes de junio, una real cédula insistía en esta reforma educativa y reiteraba que se enseñara el canon de locis theologicis y la teología moral por Natal Alexander y Daniel Concina, respectivamente, para «desterrar la laxitud en las opiniones morales [...] y para que se restablezca la moral cristiana y su pureza [...] para que la fe y la verdad sean guardadas como es justo». ${ }^{79}$

Esta reforma fundamental debe ser considerada, ya que los dos autores recomendados para la teología moral eran famosos rigoristas, que se habían destacado por la polémica contra la doctrina del probabilismo. Los libros de Natal Alexander fueron adoptados por muchas universidades españolas peninsulares, por ejemplo en la Complutense, en uno de los planes que el grupo liberal envió

\footnotetext{
${ }^{76}$ Lorandi, A. M. 2008: 88.

${ }^{77}$ Saranyana, J. I. (dir.); Alejos Grau, C.-J. (coord.). 1999: 195, nota 19.

${ }^{78}$ Pueyrredón, A. 1953. Algunos aspectos de la enseñanza en la Universidad de Córdoba durante la Regencia Franciscana: 4, 7 Córdoba: Universidad Nacional de Córdoba- Instituto de Estudios Americanistas.

${ }^{79}$ Furlong, G. 1952: 215.
} 
en 1771 al Consejo de Castilla, ${ }^{80}$ también en los estudios de teología moral del plan de 1774 de la Universidad de Oviedo y en el de 1776 de la Universidad de Granada, al igual en este caso, que Daniel Concina. ${ }^{81}$

Los dominicos Alejandro Nöel (1639-1725) conocido en España e Indias como Natal Alexander o Alejandro y Daniel Concina (1686-1756), formaban parte de los probabilioristas, que en general eran todos filojansenistas, aunque cuidaron entre ellos esos epítetos por haberse condenado muchas de las tesis sostenidas por el grupo. Alexander era francés, había sido director del colegio San Jaime en París y había conformado el grupo de los «apelantes» contra la Bula Unigenitus. Su Historia Eclesiástica se había incluido en el Index romano en 1684.

Concina, de origen alemán para la época, vivió en Italia casi toda su vida. Estudió en el colegio jesuita de Görz y fue protegido de los papas Clemente XII y Benedicto XIV. San Alfonso María de Ligorio lo llama autor «rigidísimo», pero con la correspondiente cautela y expurgando de sus obras «lo que tuvieran digno de censura». Escribió Storia del probabilismo e del rigorismo (1743/48), que fue traducido al castellano y el tratado Ad Theologiam Christianam dogmatico-moralem apparatus (1749/51). Fue un acalorado protagonista de los debates contra los jesuitas, por eso es de esperar que su obra fuese promovida por Carlos III y los reformistas para desterrar el probabilismo, como dicen Josep-Ignasi Saranyana y Carmen-José Alejos Grau, no se sabe si por convicción religiosa propia del rey o por haberse sostenido corporativamente por los jesuitas. ${ }^{82}$

Esteban Llamosas, quien ha estudiado algunos aspectos del pensamiento de Concina en la edición castellana de su obra de 1772, concluye que las tesis del autor reforzaban las ataduras del súbdito para con su rey, lo que fortalecía la autoridad de la corona, en una comparación que hace con el probabilismo. Además destaca la importancia que adquirió en teología moral este autor luego del extrañamiento ignaciano. ${ }^{83}$

El probabiliorismo enunciado técnicamente exige elegir siempre la sentencia más probable, ello explica por qué también se buscaba la vuelta a las fuentes, pidiendo la enseñanza teológica por san Agustín y santo Tomás, autoridades cuyas órdenes religiosas también adherían al sistema probabiliorista.

\footnotetext{
${ }^{80}$ Álvarez de Morales, A. 1979. La Ilustración y la reforma de la Universidad en la España del siglo XVIII: 132. Madrid: Pegaso.

${ }^{81}$ Ibídem, 134, 136.

${ }^{82}$ Saranyana, J. I. (dir.); Alejos Grau, C.-J. (coord.). 1999: 195-197.

${ }^{83}$ Llamosas, E. F. 2006. «Un teólogo al servicio de la Corona: las ideas de Daniel Concina en la Córdoba del siglo XVIII», Revista de Historia del Derecho 34: 168-169, 178-182.
} 
Tomás era un pilar fuerte dentro de la Iglesia y no se lo podía prohibir ni desplazar. Por otra parte, los mismos temas sobre la teología política, urticantes para la monarquía en la versión jesuítica, el Doctor Angélico los expresaba más moderadamente y en algunos casos hasta de otra manera.

Por ejemplo, la concepción tomista sobre la sociedad política, expuesto en De Regimine Principum se apoya, en última instancia, en la servidumbre natural del hombre, concepto que había superado la Escuela de Salamanca. Para Tomás la sociedad no es igualitaria, pues sería antinatural. Los componentes de la misma son diferentes y diferente su poder y operación, el noble tiene mayores gastos que el ciudadano común. ${ }^{84}$ Por eso, una sociedad será perfecta cuando cada uno ocupe el lugar que le corresponde.

De estos conceptos se desprende una actitud diferente de la sociedad hacia el tirano, quien dirige sus miras a su propio beneficio sin tener en cuenta el bien común de sus súbditos:

«El régimen tiránico no es justo, porque no está ordenado al bien común sino al bien privado del regente, como lo patentiza Aristóteles (3. Polít. cap. 3, y 8 Etic. cap. 10). Por tanto, el ir contra esta clase de régimen no tiene nada de sedicioso; a no ser que esto se ejecute de una manera tan desordenada, que la multitud puesta debajo de su obediencia sufra mayores daños con los trastornos consiguientes al alzamiento, que con el régimen del tirano. El sedicioso verdadero es el tirano: el cual alimenta las discordias y las sediciones en el pueblo puesto debajo de su obediencia, para poder dominar con más seguridad. Porque esto es tiránico, por ser dirigido al bien privado del presidente con perjuicio de la multitud». ${ }^{85}$

A simple vista este extracto de la Summa Theologica, nos puede parecer igual a lo sostenido por Suárez, mas la diferencia está en la división que hace Tomás de Aquino del régimen tiránico. Existen dos tipos: la tiranía moderada y la intolerable. En la primera el príncipe legítimo abusa de su autoridad, pero lo hace con cierta templanza y sin perturbar la tranquilidad pública. La segunda, el

${ }^{84}$ Peña, R. I. 1986. Los sistemas jurídicos en la enseñanza del Derecho en la Universidad de Córdoba (1614-1807): 169. Córdoba: Academia Nacional de Derecho y Ciencias Sociales de Córdoba.

${ }^{85}$ Santo Tomás de Aquino, Summa Theologica, 2. 2., q. 42, art. 2 ad $3^{\text {um. }}$ «Regimen tyrannicum non est justum, quia non ordinatur ad bonum commune sed ad bonum privatum regentis, ut patet per Phil. in 3, Polit. cap. 5 et in 8, Ethic. cap. 10. Et ideo perturbatio hujus regiminis non habet rationem seditionis: nisi forte quando sic inordinate perturbatur tyranni regimen, quod multitudo subjecta majus detrimentum patitur ex perturbatione consequenti, quam ex tyranni regimine. Magis autem tyrannus seditiosus est, qui in populo sibi subjecto discordias et seditiones nutrit, ut tutius dominari possit. Hoc ennim tyrannicum est: cum sit ordinatum ad bonum proprium præsidentis cum multitudinis nocumento».

Hispania Sacra, LXV

131, enero-junio 2013, 309-359, ISSN: 0018-215-X, doi: 10.3989/hs.2013.010 
tirano excede de una manera enorme los límites de la razón, maltratando a los ciudadanos y perturbando el orden público. ${ }^{86}$

En las soluciones dadas por el Doctor Angélico para la primera, aconseja resistir por el corto tiempo que dure, sin envolver a la nación en mayores peligros. Para la segunda, sólo se puede proceder con el juicio y arbitrio de la autoridad pública ${ }^{87}$ y de no poder obtenerse ningún auxilio humano contra el tirano, debe recurrirse a Dios. Lo que no aclara el Aquinate son las características claras que deben tener una y otra tiranía para ser calificadas de moderada o intolerable. Estos planteos favorecían los intereses borbónicos regalistas sobre las universidades y la formación de una burocracia estatal leal a sus principios ideológicos.

Pero, lo ordenado desde reales cédulas e instrucciones ¿se cumplía en la práctica? ¿Los autores por los que se ordenaba que se siguiese la enseñanza eran acatados? La respuesta debe ser buscada en los testimonios de época, no sólo constatar si el libro estaba en los anaqueles. En un informe del magistral de la Catedral de Buenos Aires, Dr. Juan Baltasar Maziel, al virrey D. Juan José de Vértiz y Salcedo en 1778, sobre la reincorporación de los colegiales del Seminario de Loreto a la universidad, describía los cursos y los exámenes realizados en base a la Summa Theologica de santo Tomás. «Como quiera que ninguno puede aspirar al grado de Doctor - decía - sin que después de haver concluido los cursos de Philosofía y Theología, exercida por dos años la pasantía, defendiendo en funciones separadas toda la Theología según el Orden de la materia que sigue en su Summa n[ues]tro Angélico Doctor» ${ }^{88}$

En un título de grado expedido en 1783, se declara haberse estudiado la teología por Tomás de Aquino, aunque este testimonio debe relativizarse, pues era un requisito de las constituciones universitarias el seguirse la teología por el Aquinate, por ello, independientemente del comentarista del Angélico Doctor que se siguiera, se puede haber colocado una frase retórica en el título por un escrupuloso secretario, atento más a las constituciones que a una verdadera enseñanza. El título dice: «los Padres Lectores Fray Pantaleón Benites y Fray Juan Josef Cassal, de la Orden de San Francisco, han pasado el comúnmente

\footnotetext{
${ }^{86}$ Mendivé, J., S. J. 1887. Elementos de Derecho Natural: 293 Valladolid: Imprenta y Librería de la Viuda de Cuesta é Hijos.

${ }^{87}$ Ibídem, 297.

${ }^{88}$ Colección documental «Mons. Dr. Pablo Cabrera», Biblioteca Central «Elma Kolhmeyer de Estrabou», Facultad de Filosofía y Humanidades, Universidad Nacional de Córdoba. Ex Instituto de Estudios Americanistas (en adelante IEA), colección documental «Mons. Dr. Pablo Cabrera», doc. $\mathrm{n}^{\circ}$ 1268 .
} 
llamado Examen General de Ignaciana, sobre todas las partes del Divino Tomás para alcanzar el laurel de Doctorado en Teología». ${ }^{89}$

Sin embargo, la enseñanza Angélica está atestiguada en un claustro universitario celebrado el 24 de febrero de 1773. Allí el rector de la universidad Fr. Pedro Nolasco Barrientos explicaba a los maestros y egresados la conveniencia de la asistencia a la función de la fiesta de santo Tomás que se celebraba en el convento de Predicadores «no solo por la congruencia de razón de seguirse la doctrina de dicho Santo Doctor en esta Universidad y su semejante asistencia observada en otras Universidades, mas también porque los Reverendos Padres Dominicos se habían comprometido a asistir a todas las funciones literarias y actos públicos de concurrencia en dicha Universidad lo que redunda en lustre de ella». ${ }^{90}$ Todos fueron del parecer de asistir como cuerpo - universidad y Colegio de Monserrat - con las insignias propias de cada facultad.

Todo el tratado de Filosofía Moral que dictó en 1774 el franciscano Mariano Ignacio Velazco en la Universidad de Córdoba sigue el método y la tradición tomista. Aunque la Ética formaba parte del primer curso de la Filosofía, como hemos dicho, no puede negarse que los lectores franciscanos lo seguían. En la introducción a la obra de este seráfico, que escribe Celina Ana Lértora Mendoza refiere que en la misma hay intereses teológicos y no sólo filosóficos y que la fuente principal es la Summa Theologica del Aquinate. ${ }^{91}$

Respecto al uso de los autores rigoristas mencionados existe una breve biografía, que escribió un contemporáneo sobre Nicolás Videla del Pino, egresado de la universidad y más tarde obispo de Salta, quien menciona en su formación a Natal Alexander. Dice que «pasó con otro compañero suyo toda la Theología Moral por tres Autores diferentes executando lo mismo con todo el derecho Canónico, e Historia Eclesiástica por Natal Alejandro». ${ }^{92}$

De todos los documentos mencionados para mostrar el fiel cumplimiento de lo ordenado por los reales decretos, el más representativo - tanto por su importancia como por la riqueza informativa - es el extenso memorial que el deán de la Catedral de Córdoba, Antonio González Pavón dirigió en 1774 al presidente del Consejo Extraordinario de España. En él, al hablar de la teología, decía:

\footnotetext{
${ }^{89}$ IEA, colección documental «Mons. Dr. Pablo Cabrera», doc. n 1375 . «Patres Lectores, Fratrem Pantaleonem Benites, ac fratrem Joannem / Josephum Cassal Ordinis Sancti Francisci; Examen Generale Ignatiana communiter dictum, super omnibus Divi Thomæ Partibus iniisse pro Doctoratus laurea in Theologia asequenda».

${ }^{90}$ AGHUNC, Libro de claustros $\mathrm{n}^{\circ}$ 1, f. 121.

${ }^{91}$ Lértora Mendoza, C. A. 2009. «Introducción», a M. I. Velazco, Filosofía Moral 1774: 11, 15-16.

${ }^{92}$ Altamira, L. R. 1943: 218. Obsérvese que la obra citada estaba prohibida en el Index desde 1684.
} 
«La Teología escolástica procuran cimentarla bien en la positiva y sin cuestiones inútiles y puramente especulativas [...] El augusto Doctor Santo Tomás es el que sirve de norma y pauta en la Universidad, conforme a las últimas reales determinaciones sobre esta materia y a cuya doctrina se procuran los jueves festivos en que tienen sus Academias y dan Melchor Cano de Locis Theologicis en estilo claro y comprensivo y, dictan Teología moral por la letra del Padre Fray Daniel Concina, encomendada también por orden de S. M. Sobre estos estudios se tiene el de la explicación de la historia todos ajustar puntualmente los maestros [...] Leen asimismo a sus conferencias los estudiantes por el Padre Gravezón, a causa del estilo comprensivo del autor y por el acierto con que concilia la noticia de la Historia Eclesiástica con la precisa y necesaria de la profana». ${ }^{93}$

En la contienda entre el clero secular y los franciscanos el deán González Pavón se mostró simpatizante de los administradores de la universidad y posiblemente escribió con cierto apego a las disposiciones regias, pues el informe iba nada menos que a un organismo peninsular. Sin embargo, como miembro del clero secular, que hablara tan prestigiosamente sobre la enseñanza universitaria de los seráficos y de la obediencia en el cumplimiento de lo dispuesto por el rey debía ser cierto. De no ser verdad podía causar el ridículo entre sus pares con quienes estaba enfrentado, más si se tiene en cuenta que el memorial está redactado en un año clave de la contienda entre franciscanos y seculares por el gobierno de la universidad.

También las Constituciones de la corporación reformadas por el obispo San Alberto recomendaron la compra de textos como la Teología del dominico tomista probabiliorista Jean Baptiste Gonet (1616-1681) y la Summa Theologica de santo Tomás y, para la moral a Daniel Concina, Echarri, Ferrer o Larraga «ilustrados con todos en estos últimos años, y reducidos a un doctrina sana y segura en todas sus partes». ${ }^{94}$

El punto más álgido del reformismo borbónico que buscaba una formación distinta de las elites, persiguiendo la formación de una burocracia leal a la Monarquía, se dio cuando los franciscanos fueron separados de la administración en enero de 1808 y, finalmente, la corporación fue entregada a la clerecía secular. Por una parte, se logró cumplir los anhelos de secularización que había querido como parte de sus reformas Carlos III y que continuó su sucesor y, por otro, el deán Gregorio Funes que quedó como rector universitario, redactó y puso en vigencia un nuevo plan de estudios que retomó los últimos aspectos del reformismo de Carlos IV.

${ }^{93}$ Bustos, Z. 1901. Anales de la Universidad Nacional de Córdoba. Segundo Período. t. I: 484-485. Córdoba: Imprenta y casa editora de F. Domenici.

94 «Constituciones redactadas por el Illmo. Obispo Fray José Antonio de San Alberto», Constituciones de la Universidad de Córdoba... tít. X, const. 93. 
Lamentablemente el texto del plan está perdido hasta hoy, pero en 1945 Carlos Luque Colombres, luego de una intensa búsqueda, debió conformarse con una reconstrucción en los aspectos fundamentales en base a la nota de elevación al poder virreinal, la aprobación que dio el entonces gobernador y capitán general del virreinato Santiago de Liniers y las menciones que de su implementación quedaron en documentos alternos como los libros de claustro universitarios..$^{95}$

El plan fue un arreglo al presupuesto disponible, por lo que de trece cátedras que ordenaba la real cédula del $1^{\circ}$ de diciembre de 1800 , sólo se constituyeron diez. Algunas desaparecieron, otras se crearon y todas se modificaron en torno a la enseñanza, aunque no de la bibliografía, que debió conformarse en torno a lo que circulaba en la mayoría de las veces.

Lugares teológicos - locis theologicis - quedó constituida como cátedra a dictarse año de por medio y formaría parte de la Facultad de Artes, debiendo cursarse sólo por aquellos que seguirían estudios eclesiásticos ${ }^{96} \mathrm{El}$ autor recomendado siguió siendo el gran dominico salmantino Melchor Cano, que como hemos visto ya se empleaba durante la administración franciscana.

La teología escolástica se siguió por el comentario del dominico Charles René Billuart, quien como hombre del siglo XVIII había intentado adaptar la ciencia de Dios a las exigencias de una época en la que los problemas históricos ponían en crisis los principios de la teología especulativa. Su obra de carácter enciclopédico (19 volúmenes), tuvo mucho éxito a partir de un compendio que realizó para la enseñanza de la juventud en sólo seis tomos. Era un acérrimo tomista que encajaba debidamente en los planes regios de reforma, además de ser un jansenista que también escribió varios escritos polémicos contra la bula Unigenitus (1713) de Clemente XI que había condenado en bloque 100 proposiciones de la obra del jansenista Antoine Arnald Reflexiones morales.

En la enseñanza de la teología moral se siguió al rigorista Charles François Houbigant, reemplazado luego por el igualmente rigorista Ignacio Jacinto Amat de Graveson. ${ }^{97}$

En derecho canónico se intentó introducir a Carbo Sebastiano Berardi pero, por petición del catedrático, se lo reemplazó por Giulio Lorenzo Selvaggio, pues «teniendo todos sus discípulos al Selvaggio y no al Bardi, parecía más conducente al mejor aprovechamiento de los estudiantes, que estudiasen por el

${ }^{95}$ Luque Colombres, C. 1945. El primer plan de estudios de la Real Universidad de San Carlos de Córdoba (1808-1815). Córdoba: Cuaderno de Historia XIII, Universidad Nacional de Córdoba, Instituto de Estudios Americanistas, 1945. (también en: Para la Historia de Córdoba, Córdoba, Biffignandi, 1971: 319-346).

${ }^{96}$ Ibídem, 326.

${ }^{97}$ Ibídem, 329-330. 
primero y no por el segundo». ${ }^{98}$ Esto sugiere la posibilidad de que Selvaggio haya sido el texto seguido durante la regencia franciscana, ya que había mayor número de ejemplares entre los alumnos que estaban cursando.

En el siglo XVIII español, por influencia francesa el vocablo «jansenismo» se convirtió en un término abarcativo de muchas posiciones en defensa del regalismo y contra el absolutismo pontificio, y se caracterizó por un haz de antijesuitas, rigoristas, conciliaristas y episcopalistas que poco o nada tenían que ver con la herejía primigenia.

Habían sido los jesuitas, quienes en un fuerte debate con los jansenistas, habían englobado - desvirtuando el término - a todo aquél que defendiera a las Iglesias nacionales, un ius proprium de naturaleza canónica, o simplemente les hiciera la guerra. ${ }^{99}$

En la Universidad de Córdoba, después del extrañamiento de la Compañía de Jesús, la bibliografía indicada para las cátedras de teología escolástica, moral y derecho canónico tuvo un predominio de la orden de predicadores. Natal Alexander, Daniel Concina, Melchor Cano, Charles René Billuart e Ignacio Jacinto Amat de Graveson, lo fueron. La enseñanza seguía la tónica de la reforma borbónica de volver la teología a las raíces tomistas y agustinianas pero, además del grupo de dominicos, otros expositores de Tomás habían abrazado el probabiliorismo y algunos franceses eran filojansenistas o jansenistas como Billuart. Creemos que sería una exageración pensar que en la Universidad de Córdoba se enseñaban las doctrinas jansenistas por la existencia de algún autor que simpatizaba con ellas, cuyo texto se seguía en las aulas.

El probabiliorismo reforzaba en la formación cultural de las elites el proyecto regalista borbónico, por ello este aspecto de la praxis política del rey también tuvo su justificación teológica. Así, el regalismo español del siglo XVIII tuvo dos vertientes - como lo ha señalado Salvador Albiñana - ${ }^{100}$ la corona, que porta la palabra referida al poder temporal y legitima la intervención del brazo secular en los asuntos eclesiásticos y, la otra, que ha dado en llamarse galicanismo - a fuer de un mejor término-, que se dirige al poder espiritual exaltando las decisiones conciliares y episcopales en detrimento del poder pontificio y reforzando, en consecuencia, la figura del obispo. La primera, se extiende a los intereses del despotismo español y a los ilustrados, en tanto, la segunda adquirió importancia en

\footnotetext{
${ }^{98}$ Ibídem, 332.

${ }^{99}$ Llamosas, E. F. 2006. «Jansenismo, regalismo y otras corrientes en la Universidad de Córdoba», Cuadernos de Historia. 16: 153-173.

${ }^{100}$ Albiñana, S. 1989. «Leyes y Cánones en la Valencia de la Ilustación», Claustros y estudiantes. t. I: 12. Valencia: Universidad de Valencia, Facultad de Derecho.
} 
amplios sectores de la Iglesia española que, en una unidad de miras coincidieron en sus propósitos reformistas.

En 1793, un estudiante universitarios Jerónimo de Salguero Cabrera y Cabrera, defendió en la Universidad de Córdoba un acto público. Allí procuró mostrar las nuevas concepciones del derecho que se enseñaban desde la cátedra de Instituta, que se había fundado en 1791. De sus Asserta Juridica, sale a la luz un cuerpo de doctrina regalista y galicana defendida en sus postulados más significativos.

Salguero de Cabrera y Cabrera inició sus asserta con un párrafo extraído de la obra del obispo de Meaux, Jacques Benigne Bossuet, Defensio Declarationis Cleri Gallicani (1682), libro VI, capítulo 29:

«No juzgamos deshonor el que teólogos y cristianos defendamos los derechos regios, no tanto como derechos regios, cuanto como mandatos de Cristo; mandatos, digo, de Cristo, que ordena la república y el imperio de la tranquilidad, para que en el Imperio de la Iglesia futura, libre ya de discordias, sirva mejor a Dios: no parece bien que so color de religión se arruinen los reinos, a los cuales la religión debe servir de tutela». ${ }^{101}$

Intenso contenido galicano y regalista se encuentra en el extracto elegido, la figura del poder regio aparece como autoridad divina equiparada a la del papa, donde las decisiones pontificias si no convenían a la Monarquía - «so color de religión se arruinen los reinos»-, eran de juicio reformable.

La génesis de esta obra de Bossuet y los motivos de su aparición están íntimamente ligados a la historia de Francia y su particular visión del mundo de las ideas, todo ello enmarcado en una realidad más amplia, cual es la discusión dentro de Iglesia respecto a la autoridad pontificia, que incidió en las concepciones sobre la autoridad temporal de todas las monarquías cristianas. Bossuet y sus ideas habían entrado a España y sus colonias de la mano de la nueva dinastía francesa.

${ }^{101}$ Archivo General de la Nación (Buenos Aires), sala IX, sección Justicia (31-6-3), leg. 30, exp. 881, Jerónimo de Salguero Cabrera y Cabrera, Asserta Iuridica / Deprompta ex duobus primis Institutionum Imperatoris Justiniano / Libris, prorsus consona tùm Legibus Hispanis, tùm rationi, nonnullisque aliis prælucentibus / Thæssibus in percelebri Corduvensi Licæo propugnanda; / Quæque. / Ill[ustrissi]mo, àc R[everendissi]mo D[omino] D[octo]ri D[omino] Angelo Mariano Moscoso huius Corduvensis Civitatis, nècnon Te/cumanæ Provintiæ meritissimo Antistiti, Regis à Consiliis et[ceter] a et[ceter]a et[ceter]a / D[edicat] O[ffert] C[onsacrat], f. 2v. «Non dedecori ducimus, quod Theologi, christianique jura Regia defendimus, non tàm ut jura Regia, quàm ut Christi placita: / Christi, inquam, placita, Rempublicam ordinantis, tranquillantis imperium, ut Ecclesia in Imperio futura jàm à seditionibus libera / melius Deo serviat: néc placet Religionis specie Regna pessundari, quibus Religio tutelæ esse debeat /».

Hispania Sacra, LXV

131, enero-junio 2013, 309-359, ISSN: 0018-215-X, doi: 10.3989/hs.2013.010 
Dos corrientes antagónicas estaban indirectamente relacionadas con el exordio que Salguero y Cabrera escribía en sus conclusiones. La primera llamada ultramontanismo consideraba a la autoridad de Roma «más allá de las montañas» - ultra montes - . El papa era el «obispo universal» - episcopus universalis - y resaltaban su superioridad respecto de los demás obispos. La corriente estaba representada en un principio sólo por italianos, luego del Concilio de Trento, encontró varios adeptos entre los ibéricos y flamencos. Una de las principales depuradoras y sustentadoras de esta doctrina fue la orden de la Compañía de Jesús, con su comentarista Francisco Suárez. La concepción fue variando con los siglos, pasando desde posturas extremistas hasta algunas más moderadas ya en el siglo XVII. Descollaron Juan de Torquemada $(\uparrow 1468)$ y el cardenal Cayetano y Roberto Belarmino. ${ }^{102}$

La segunda, liderada por la Universidad de París, rechazaba la fórmula episcopus universalis. Para ella Cristo mismo había instituido a los obispos, siendo éstos sucesores de los apóstoles. La postura de los doctores sorbonenses ha pasado a la historia con el título de galicanismo. Todos los intentos de introducir la doctrina ultramontana en Francia fueron condenados por la Universidad de París implacablemente. ${ }^{103}$ Dentro de este grupo estaban Juan de París (†1306), Pedro d'Ailly (†1420), Juan Gersón (†1429), Santiago Almain $(† 1515)$ y, por supuesto, Jacques Benigne Bossuet.

Dentro de la lucha de ambos grupos antagónicos, el tema del conciliarismo, es decir, la supremacía del concilio sobre el papa, fue de importancia capital. El mismo era enseñado corrientemente por la Universidad de París desde principios del siglo Xv y será defendido en los concilios de Constanza (1415) y Basilea (1431), liderado este último por los doctores de La Sorbona de donde salía la elite intelectual del clero. ${ }^{104}$

La obra de Bossuet aparece en medio de las desavenencias entre Luis XIV e Inocencio XI, que tuvo por causa inmediata la extensión de la regalía a todo el reino francés, opuesto a lo determinado por el concilio de Lyon (1274). El Rey Sol en 1673 formula una declaración por la cual sustituía al obispo cuando vacaba una diócesis y cobraba y administraba las rentas episcopales y, además nombraba los cargos y beneficios parroquiales que estuviesen vacos, e impuso la aceptación de esa doctrina a todo el clero secular o regular de su reino. Inocencio XI elevó numerosas protestas en 1678 y en 1679, por lo que el monarca planteó un desquite en el terreno doctrinario convocando a la Asamblea del Clero

${ }^{102}$ Tonda, A. 1982. El pensamiento teológico del Deán Funes. t. I La Iglesia: 88. Santa Fe: Universidad Nacional del Litoral.

${ }^{103}$ Ibídem, 89.

${ }^{104}$ Ibídem, 100-121. 
francés que se reunió en París en 1681. Concluyó en 1682 con la Declaratio cleri galicance de potestate ecclesiastica, que incluía cuatro puntos del regalismo más extremo, que básicamente era un reduccionismo a la mínima expresión del poder espiritual y temporal de los pontífices. ${ }^{105}$

Bossuet escribe su Defensio para explicar los malos entendidos, aunque es partidario del conciliarismo y que una decisión pontificia necesita del acuerdo episcopal para imponerse a toda la Iglesia. ${ }^{106}$ Por esta razón el párrafo introductorio de las conclusiones de Salguero de Cabrera y Cabrera en Córdoba es clave en la comprensión del galicanismo moderado, adoptado por la universidad. De esta manera podemos ver como, además del probabiliorismo, otras dos nuevas corrientes, el regalismo y galicanismo, que tenían su base en la primera, se estaban enseñando a las elites en esta segunda etapa de los estudios teológicos.

\section{ConClusiones}

El Tucumán presentó diversos espacios para la formación de la cultura teológica de sus elites, pero el que concentró los de mayor competencia fue Córdoba y su universidad. A sus administradores, jesuitas o franciscanos, los grupos dominantes delegaron la formación de su prole que implicaba detentar y transmitir los valores imperantes sobre el deber ser y parte de los recursos simbólicos que los mostraban como los depositarios de un conocimiento dominante que se buscaba legitimar y los legitimaba como tales. La universidad era un organismo que contribuía a la consolidación de redes de sociabilidad que resultaban operativas para el grupo.

Esta característica se continúa en las dos etapas históricas en que hemos dividido el trabajo, a pesar de las diferencias que hubo entre ambas.

Resulta adecuado ya, responder el interrogante planteado en el título del trabajo y delinear cómo se daba en la práctica. El eje por el cual pasaba toda la vida universitaria, y desde donde se debía mirar la realidad, era la teología. En sus especialidades de la moral — «el deber ser»-, como de la política — «el poder ser»-, marcaba las pautas culturales y de comportamiento de la sociedad y los órdenes político y jurídico que se debían implementar. No se puede entender a la filosofía y al derecho sin las fuentes teológicas, ya que la normativa y la regulación social estuvieron imbuidas de conceptos emanados de ellas. Es más, si bien las reformas borbónicas introdujeron otra preceptiva de organización

\footnotetext{
${ }^{105}$ Saranyana, J. I. (dir.); Alejos Grau, C.-J. (coord.) 1999: 200-201.

${ }^{106}$ Tonda, A. 1982: 129, 130.
} 
política y social, no dejaron de estar centradas en una perspectiva teológica del mundo, con un destino del hombre que compartieron y que no cuestionó ningún nuevo sistema.

La formación cultural partía de planteos pragmáticos, en gran parte vinculados a la sociedad a la cual pertenecían los estudiantes, que aunque todavía no detentaban un pleno dominio del campo simbólico de su condición de elite, sí formarían parte íntegra de sus filas con todas sus prerrogativas una vez egresados. Los problemas considerados de interés por entonces, tanto en el plano teológico como jurídico, también estaban vinculados al plano social, con miras a solucionar algunas inquietudes que partían de su faz espiritual o, simplemente brindar los conocimientos y destrezas necesarias para cumplir con el disciplinamiento social hasta donde las leyes no alcanzaban. El estudiante, si el objetivo de su formación era el eclesiástico, debía estar preparado para los requerimientos puntuales del confesionario o del púlpito; el desempeño de las múltiples ocupaciones de un párroco, capellán o doctrinero; conformar los jurados de oposiciones a curatos; o de los impedimentos para la concesión de los sacramentos y de cómo se podía llegar a una solución práctica.

Si el objetivo no era la ordenación in sacris, la formación estaba destinada a contribuir a un prestigio que, como partícipe de los grupos de poder, el estudiante poseía. Luego de egresado se dedicaría a incrementar el patrimonio familiar, manejando las empresas comerciales que ya sus ancestros habían puesto en marcha, pero la formación en los órdenes normativos daba un dominio simbólico del campo desde un aparato ideológico que lo legitimaba. También podía intentar hacer carrera en la burocracia estatal desde los cargos capitulares, hasta la real hacienda y real audiencia.

El casuismo fue una característica esencial, por lo menos hasta 1767 , se sometía al estudiante teólogo a casos hipotéticos, sacados de la experiencia cotidiana y se le daban algunas resoluciones de casos y, en otros debía buscarlas él mismo a la luz de un corpus de doctrina y de razonamientos prácticos.

Los dos temas de las fuentes - los impedimentos de matrimonio y la bula de cruzada - eran temas centrales, conflictivos y habían provocado redefiniciones y reconstrucciones luego de la reforma protestante. En el estudio de ambas temáticas se aunaban esfuerzos entre la Iglesia católica y las monarquías, en este caso la hispana. Las recaudaciones de la Real Hacienda por la venta de bulas en el tratado de Orosz, y el establecimientote los herederos legítimos en el de Hidalgo, eran problemáticas de orden público a cuya solución había contribuido la Iglesia a pedido expreso o tácito de los soberanos seculares. Por eso estas temáticas integrantes de los programas universitarios y el desarrollo de las mismas no estaban puestas al azar. Cada pieza se movía completando el rompecabezas en el que la Monarquía, la Iglesia y las elites se daban coherencia a sí 
mismas y gobernaban. Por eso desde las temáticas y su tratamiento se advierte la producción de un discurso que construye y contribuye a solidificar un determinado orden social y una «cultura legítima», en palabras de Ángel Rama en La ciudad letrada..$^{107}$

Por otra parte estas problemáticas, tratadas desde la cátedra, formaban parte de la realidad cotidiana local y eran un tema candente, sobre todo en América, que presentaba problemas interétnicos a los cuales el derecho y la teología tradicional, pensados desde el centro a la periferia, no podían dar todas las respuestas. Por eso, difícilmente la teología y el derecho canónico que formaba la cultura de elite, fueran ciencias etéreas, encargadas de desentrañar sólo los atributos de la Divinidad, como las vio la historiografía universitaria cordobesa tradicional.

El probabilismo fue la corriente teológica que en la primera etapa adhirieron los profesores y los egresados en la primera etapa, pues la orden de la Compañía de Jesús lo había abrazado como doctrina; como así también se embanderaron en las filas antijansenistas. Ello ha quedado patente en las formas de resolver las disputas que se enumeran en los tractatus, pero también en la normativa que emanó de la corporación universitaria y la expresa prohibición de no aceptar alumnos a cursar o a exámenes, que viniendo de otras casas de formación hubiesen estudiado por escuelas diferentes a la jesuítica.

La manera de enseñar el probabilismo en la universidad era en algunos aspectos coercitiva, pues aunque se le enseñaban las opiniones en contrario sobre algunos temas, se las mostraba como falsas.

Los autores elegidos y citados expresamente en los tractatus, que tenían ejemplares de libros en la biblioteca y no eran meras citas de fuentes secundarias, eran en su mayoría probabilistas y jesuitas, aunque, nobleza obliga decir, que eran los autores de moda del momento, citados en otras universidades indianas y peninsulares. Se privilegiaba la cita de los mejores canonistas y moralistas que estuvieran al alcance en la biblioteca. Es de destacar que la influencia en el egresado era tal, que un examen de las citas de los alegatos, de las sentencias, etc. en los expedientes de los Juzgados Eclesiásticos y Civiles donde les tocó actuar, se percibe prácticamente a los mismos autores y títulos con los que se habían formado en las aulas.

En la segunda etapa, posterior a la expulsión de los ignacianos, el probabiliorismo fue la doctrina dominante y legitimada desde las aulas. No en vano la universidad se confió a los franciscanos, pues ellos habían aceptado la corriente y la habían desarrollado mucho más que los propios dominicos, sus acérrimos defensores.

${ }^{107}$ Rama, A. 1984. La ciudad letrada: 25 Montevideo: FIAR. 
Además que se planteaba el retorno a las fuentes agustinianas y tomistas, los autores elegidos para la enseñanza eran rigoristas y filojansenistas, aunque se buscaba callar este último apodo, porque el Papado había condenado los libros de Janssen. El planteo del retorno a la «sana doctrina» de Agustín y Tomás se producía porque ambas órdenes adherían a la corriente probabiliorista, más que un pastoril deseo de abrevar en las vertientes y pacer en los prados de la más «pura y primigenia» doctrina.

Estos autores contribuían mejor a sujetar los lazos de los súbditos para con sus soberanos y a ligar mejor a la sociedad con el aparato de dominación.

La normativa también cambió, pues en 1783 se reformaron por un obispo regalista las constituciones universitarias del siglo XVII. En ellas se dejó expresa constancia de los nuevos autores que debían seguirse en las cátedras, en su mayoría probabilioristas y filojansenistas, con un sustancial predominio de los dominicos. Los autores que acordaban con los nuevos lineamientos monárquicos para la formación de las elites y de los nuevos cuadros de su burocracia, respondían así al reformismo monárquico de las universidades.

Otra corriente teológica que se introdujo de la mano de la dinastía borbónica fue el galicanismo o conciliarismo, que indicaba la supremacía de las decisiones conciliares por sobre la autoridad pontificia, y coadyuvaba a los nuevos intereses regalistas. Este pragmatismo, también es abarcativo en el servir a la Monarquía y adaptarse a sus intereses de momento.

Este conocimiento, con sus permanencias y sus cambios, se perfiló como el más fiable y receptado, asimilado y reproducido por el grupo. Su posesión los hacía, junto a otros de iguales centros, partícipes de una misma comunidad. El estudiar en Córdoba, y continuar en Chile, Chuquisaca o el Cuzco, cuando no Alcalá, permitía incorporarse sin problemas ni desfasajes académicos al «gremio de universidad», como así a quienes pretendían que se los recibiera en la de Córdoba, que aunque no fueron muchos, no hubo oposición para aceptar sus títulos provenientes de otras universidades. En cambio, a aquél que ya habiendo cursado o egresado, que por una lenta averiguación de sus orígenes familiares se lo consideraba indigno de pertenecer a ella, se lo mandaba llamar y se le retiraba el título que había acreditado la posesión de aquel saber corporativo y legitimado por generaciones.

Córdoba construyó una identidad que le llevó a constituirse en un referente peculiar en la región. Los caminos recorridos, con aciertos y desaciertos según la óptica de cada uno de sus integrantes, plasmaron una corporación que resultó en sí misma un paradigma educativo, que se adecuó a los tiempos, siendo innovadora en aquello que era útil a las nuevas concepciones que se propagaban, sin rechazar las pervivencias de antiguos saberes que podían consolidar su propia transformación. 


\section{BIBLIOGRAFÍA}

Albiñana, S. 1989. «Leyes y Cánones en la Valencia de la Ilustación», Claustros y estudiantes, t. I: 1-16. Valencia: Universidad de Valencia, Facultad de Derecho.

Altamira, L. R. 1943. El Seminario Conciliar de Nuestra Señora de Loreto. Colegio Mayor de la Universidad de Córdoba. Córdoba: Universidad Nacional de CórdobaInstituto de Estudios Americanistas.

Álvarez de Morales, A. 1979. La Ilustración y la reforma de la Universidad en la España del siglo XVIII. Madrid: Pegaso.

Álvarez Márquez, M. del C. 2000. El libro manuscrito en Sevilla (siglo XVI). Sevilla: Ayuntamiento de Sevilla- Servicio de Publicaciones.

Álvarez Márquez, M. del C. 2007. La impresión y el comercio de libros en la Sevilla del Quinientos. Sevilla: Secretariado de Publicaciones de la Universidad de Sevilla.

Astrada, E. M., Consigli J. M. 2002. Ladislao Orosz S. J. Tratado sobre la Bula de la Cruzada. Córdoba: Agencia Córdoba Ciencia.

Benito Rodríguez, J. A. 2002. La Bula de Cruzada en Indias. Madrid: Fundación Universitaria Española.

Bustos, Z. 1901. Anales de la Universidad Nacional de Córdoba. Segundo Período. t. I. Córdoba: Imprenta y casa editora de F. Domenici.

Casey, J. 1990. Historia de la Familia. Madrid: Espasa- Calpe.

Constituciones de la Universidad de Córdoba. Córdoba: Universidad Nacional de Córdoba, Instituto de Estudios Americanistas, 1944.

Chartier, R. 1994. Libros, lecturas y lectores en la Edad Moderna. Madrid: Alianza.

Chartier, R. 1996. El mundo como representación. Estudios sobre historia cultural. Barcelona: Gedisa.

Dellaferrera, N. C. 2008. Procesos canónicos. Catálogo (1688-1888). Archivo del Arzobispado de Córdoba. Buenos Aires: Editorial de la Pontificia Universidad Católica Argentina.

Donoso, J. 1852. Instituciones de Derecho Canónico Americano. t. II. París, Librería de Rosa Bouret y Cía.

Febvre, L.; Martin H.-J. 2005. La aparición del libro. México: Fondo de Cultura Económica.

Fornés, J. 1991. «El sacramento del matrimonio (derecho matrimonial)», Manual de Derecho Canónico. Pamplona: Universidad de Navarra, Facultad de Derecho Canónico.

Fraschini, A. 2005. Index Librorum Bibliothecae Collegii Maximi Cordvbensis Societatis Iesv. Córdoba: Universidad Nacional de Córdoba. 
Funes, G. 1910-1911 [1816-1817] Ensayo de la Historia Civil del Paraguay, Buenos Aires y Tucumán. 2 vols. Buenos Aires: Rosso y Cía.

Furet, F. 1990. «La librairie del reino de Francia en el siglo XVIII», en A. Petrucci (ed.), Libros, editores y público en la Europa moderna: 169-206 Valencia: Edicions Alfons el Magnànim.

Furlong, G. 1936. «Ladislao Orosz, ex profesor y ex rector de la Universidad de Córdoba (1697 - 1773)». Estudios 45: 325-347.

Furlong, G. 1952. Nacimiento y desarrollo de la Filosofía en el Río de la Plata 15361810. Buenos Aires: Editorial Kraft.

Furlong, G. 1966. Ladislao Orosz y su «Nicolás del Techo» (1759). Buenos Aires: Theoria.

Furlong, G. 1969. Historia Social y Cultural del Río de la Plata (1536-1810). Tomo II El Trasplante Cultural: Ciencia. Buenos Aires: TEA.

Gaudemet, J. 1993. El Matrimonio en Occidente. Madrid: Taurus.

Ghirardi, M. M. 2004. Matrimonios y familias en Córdoba 1700-1850. Prácticas y representaciones. Córdoba: Universidad Nacional de Córdoba - Centro de Estudios Avanzados.

Goñi Gaztambide, J. 1958 Historia de la Bula de Cruzada en España. Vitoria: Seminario Mayor.

Gorriti, J. I. de 1916 [1836] Reflexiones sobre las causas morales de las convulsiones interiores de los nuevos estados americanos y examen de los medios eficaces para remediarlas. Buenos Aires: La Cultura Argentina.

Hespanha, A. 1993. La gracia del Derecho. Economía de la cultura en la edad moderna. Madrid: Centro de Estudios Constitucionales.

Hidalgo, Fabián S. J. 2005 [1734]. Tratado acerca de los impedimentos de Matrimonio (Córdoba, 1734). Estudio, transcripción paleográfica y versión española, por Benito Moya, S. G. A.; De Santis, G. Córdoba: Centro de Estudios Históricos «Prof. Carlos S. A. Segreti».

Hirsch, R. 1990. «Imprenta y lectura entre 1450 y 1550», en A. Petrucci (ed.), Libros, editores y público en la Europa moderna: 27-70 Valencia: Edicions Alfons el Magnànim.

Lavrin, A. 1989. «Sexuality in colonial México: A Church dilemma», en Lavrin, A. (ed.), Sexuality and marriage in colonial Latin America. 47-95. Nebraska: Lincoln and London.

Lorandi, A. M. 2008. Poder central, poder local. Funcionarios borbónicos en el Tucumán colonial. Un estudio de antropología política. Buenos Aires: Prometeo.

Lorenzo Sanz, E. 1980. Comercio de España con América en la época de Felipe II. t. II: 178-184 Valladolid: Instituto Cultural Simancas- Diputación Provincial. 
Luque Colombres, C. 1945. El primer plan de estudios de la Real Universidad de San Carlos de Córdoba (1808-1815). Córdoba: Cuaderno de Historia XIII, Universidad Nacional de Córdoba, Instituto de Estudios Americanistas, 1945. (también en: Para la Historia de Córdoba, Córdoba, Biffignandi, 1971: 319-346).

Llamosas, E. F. 2006. «Jansenismo, regalismo y otras corrientes en la Universidad de Córdoba», Cuadernos de Historia. 16: 153-173.

Llamosas, E. F. 2006. «Un teólogo al servicio de la Corona: las ideas de Daniel Concina en la Córdoba del siglo XvIII», Revista de Historia del Derecho 34: 168-169, 178-182.

Martínez de Sánchez,A. M. 1994. «La Bula de Santa Cruzada. Córdoba del Tucumán en la segunda mitad del siglo XVIII», Archivum 16: 297-312.

Martínez de Sánchez, A. M. 1995. «De lo pecuniario a lo espiritual: la Bula de Composición», Revista de Historia del Derecho, 23: 199-228.

Martínez de Sánchez, A. M. 2008. «Ley y doctrina en el Tractatus de Bulla Cruciatæ de Ladislao Orosz», en Puente Brunke, J. de la, Guevara Gil, J. A. (eds.), Derecho, instituciones y procesos históricos, t. I: 159-180, Lima: Pontificia Universidad Católica del Perú, Instituto Riva-Agüero.

Martini, M. P. 1993. El Indio y los Sacramentos en Hispanoamérica Colonial. Circunstancias adversas y malas interpretaciones. Buenos Aires: Programa de Historia Colonial (PRHISCO-CONICET).

Mendivé, J., SJ 1887. Elementos de Derecho Natural. Valladolid: Imprenta y Librería de la Viuda de Cuesta é Hijos.

Nieva Ocampo, G.; González Fassani, A. M. 2008 «Relicario de vírgenes. Familia monástica en el convento de Santa Catalina de Córdoba del Tucumán (1730-1750)», en C. Folquer (ed.), La Orden Dominicana en Argentina: Actores y Prácticas: 23-54 Tucumán: Universidad Nacional Santo Tomás de Aquino, Instituto de Investigaciones Históricas.

Peña, R. I. 1986. Los sistemas jurídicos en la enseñanza del Derecho en la Universidad de Córdoba (1614-1807). Córdoba: Academia Nacional de Derecho y Ciencias Sociales de Córdoba.

Peña, R. I. 1988. «Fuentes del Derecho Indiano: los autores, Anacleto Reiffenstuel y el Jus Canonicum Universum», Anales de la Academia Nacional de Derecho y Ciencias Sociales de Córdoba 23: 111-160.

Petrucci, A. 1999. Alfabetismo, escritura, sociedad. Barcelona: Gedisa.

Petrucci, A. 2003 La Ciencia de la Escritura. Primera lección de paleografía. Buenos Aires: Fondo de Cultura Económica.

Pueyrredón, A. 1953. Algunos aspectos de la enseñanza en la Universidad de Córdoba durante la Regencia Franciscana. Córdoba: Universidad Nacional de Córdoba- Instituto de Estudios Americanistas. 
Rama, A. 1984. La ciudad letrada. Montevideo: FIAR.

Saranyana, J. I. (dir.); Alejos Grau, C.-J. (coord.). 1999. Teología en América Latina. vol. II/1 Escolástica barroca, Ilustración y preparación de la Independencia (16651810). Madrid- Frankfurt: Iberoamericana- Vervuert.

Sargiotto, E. 1994. «Matrimonio y sexualidad en Hispanoamérica colonial. Tesis historiográficas recientes en los Estados Unidos». Páginas sobre Hispanoamérica colonial. Sociedad y cultura 1.

Storni, H. 1980. Catálogo de los jesuitas de la Provincia del Paraguay (Cuenca del Plata) 1585-1768: 142 Roma: Institutum Historicum Societatis Ihesu.

Strasser, M. 1930. «El Río de la Plata visto por viajeros alemanes del siglo XVIII, según cartas traducidas por Juan Mühn, S. J.». Revista del Instituto Histórico y Geográfico del Uruguay 7: 229-325.

Szabó, L. 1984. El húngaro Ladislao Orosz en tierras argentinas 1729-1767. Buenos Aires: Fundación para el Estudio de la Ciencia y la Cultura.

Tonda, A. 1982. El pensamiento teológico del Deán Funes. t. I La Iglesia. Santa Fe: Universidad Nacional del Litoral.

Torres Gutiérrez, A. 2000. «Implicaciones económicas del miedo religioso en dos instituciones de Antiguo Régimen: la Inquisición y la Bula de Cruzada», en Milenio: Miedo y religión, IV Simposio Internacional de la Sociedad Española de Ciencias de las Religiones, Tenerife [www2.ull.es/congresos/conmirel].

Velazco, M. I. 2009 [1774] Filosofía Moral 1774. Transcripción, traducción, 